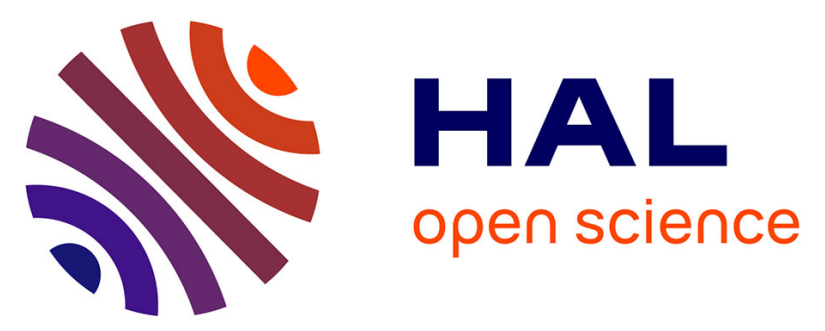

\title{
Raman and photoacoustic infrared spectra of fluorene derivatives: Experiment and calculations
}

K H Michaelian, S A Oladepo, J M Shaw, X Liu, Isabelle Baraille, Didier Bégué

\section{- To cite this version:}

K H Michaelian, S A Oladepo, J M Shaw, X Liu, Isabelle Baraille, et al.. Raman and photoacoustic infrared spectra of fluorene derivatives: Experiment and calculations. Vibrational Spectroscopy, 2014, 74, pp.33 - 46. 10.1016/j.vibspec.2014.07.003 . hal-03227487

\section{HAL Id: hal-03227487 \\ https: / hal-univ-pau.archives-ouvertes.fr/hal-03227487}

Submitted on 17 May 2021

HAL is a multi-disciplinary open access archive for the deposit and dissemination of scientific research documents, whether they are published or not. The documents may come from teaching and research institutions in France or abroad, or from public or private research centers.
L'archive ouverte pluridisciplinaire HAL, est destinée au dépôt et à la diffusion de documents scientifiques de niveau recherche, publiés ou non, émanant des établissements d'enseignement et de recherche français ou étrangers, des laboratoires publics ou privés.

\section{(이)( $)$}

Distributed under a Creative Commons Attribution - NonCommercial - NoDerivatives| 4.0 


\title{
Raman and photoacoustic infrared spectra of fluorene derivatives: Experiment and calculations
}

\author{
K.H. Michaelian ${ }^{\mathrm{a}, *}$, S.A. Oladepo ${ }^{\mathrm{a}}$, J.M. Shaw ${ }^{\mathrm{b}}$, X. Liu $^{\mathrm{c}}$, D. Bégué ${ }^{\mathrm{d}}$, I. Baraille ${ }^{\mathrm{d}}$ \\ a Natural Resources Canada, CanmetENERGY, One Oil Patch Drive, Devon, Alberta T9G 1A8, Canada \\ b Department of Chemical and Materials Engineering, University of Alberta, Edmonton, Alberta T6G 2G6, Canada \\ c Canadian Light Source Inc., 44 Innovation Boulevard, Saskatoon, Saskatchewan S7N 2V3, Canada \\ d Institut des Sciences Analytiques et de Physico-Chimie pour l'Environnement et pour les Matériaux, UMR 5254-CNRS, Equipe de Chimie Physique, \\ Université de Pau et des Pays de l'Adour, 2 Avenue du Président Angot, 64053 Pau Cedex 9, France
}

\section{A R T I C L E I N F O}

\section{Article history:}

Received 17 February 2014

Received in revised form 7 July 2014

Accepted 11 July 2014

Available online 21 July 2014

\section{Keywords:}

Raman spectroscopy

Photoacoustic infrared spectroscopy

Aromatic hydrocarbons

DFT calculations

Variational calculations

\begin{abstract}
A B S T R A C T
Raman and photoacoustic (PA) infrared spectra of fluorene and four derivatives (2,3-benzofluorene, 2-methylfluorene, 2-ethylfluorene and 1,8-dimethylfluorene) were recorded and analyzed in this investigation. Mid- and far-infrared PA spectra were examined from about 2000 to $100 \mathrm{~cm}^{-1}$. The Raman spectra spanned the same wavenumber range. Observed bands in both PA and Raman spectra were compared with DFT (harmonic) and variational (anharmonic) calculations, and with published spectra. The DFT calculations provided single-molecule frequencies, whereas the variational method yielded results for both monomeric and dimeric species. Many previously unknown bands, including numerous features due to combination and overtone transitions, were identified and assigned in this work.
\end{abstract}

Crown Copyright (c) 2014 Published by Elsevier B.V. All rights reserved.

\section{Introduction}

Photoacoustic (PA) infrared spectra of tetracene $\left(\mathrm{C}_{18} \mathrm{H}_{12}\right)$, pentacene $\left(\mathrm{C}_{22} \mathrm{H}_{14}\right)$, perylene $\left(\mathrm{C}_{20} \mathrm{H}_{12}\right)$ and pyrene $\left(\mathrm{C}_{16} \mathrm{H}_{10}\right)$ were recently obtained in our laboratory and interpreted in light of density functional theory (DFT) calculations [1,2]. The "fingerprint" and far-infrared regions (together, approximately $2000-80 \mathrm{~cm}^{-1}$ ) were studied in detail in these investigations. In addition to the predicted infrared-active bands, the PA spectra of these hydrocarbons display many features due to overtones and combinations. Moreover, numerous Raman-active (gerade) vibrations also give rise to bands in the PA spectra, which thus convey considerable information regarding the structures of these compounds.

Vibrational spectra of these, and related similar, aromatic hydrocarbons are important in two quite different contexts and both contexts motivate the present work. The first, relevant to the utilization of certain hydrocarbon feed stocks, is the need for characterization of asphaltenes. These complex and highly aromatic species arise in numerous hydrocarbon resources and are particularly abundant in bitumen derived from oil sands, heavy oils,

\footnotetext{
* Corresponding author. Tel.: +1 780987 8646; fax: +1 7809878676.

E-mail addresses: Kirk.Michaelian@NRCan-RNCan.gc.ca, michaeli@nrcan.gc.ca (K.H. Michaelian).
}

and similar substances. While asphaltenes are generally believed to consist of extended aromatic ring systems, aliphatic chains, and heteroatoms (sulphur, nitrogen and oxygen), their structural details remain the subject of much discussion and debate. Infrared and Raman spectra of asphaltenes and representative model compounds (together with other spectroscopic and non-spectroscopic analyses) are expected to provide critical information pertaining to this question. For this reason, acquisition and interpretation of vibrational spectra are key components of an ongoing research program in our laboratory. Related previous work combined spectroscopy with the determination of thermophysical properties of similar aliphatic and aromatic hydrocarbons $[3,4]$. The second originates in astrophysics and astrochemistry, where infrared absorption spectra of aromatic hydrocarbons and various forms of elemental carbon are frequently invoked in comparisons with emission spectra from the interstellar medium. The extensive detail in PA infrared spectra of aromatic hydrocarbons-particularly in the $2000-1700 \mathrm{~cm}^{-1}$ and higher wavenumber regions-enables observation of little-known combination bands involving $\mathrm{C}-\mathrm{H}$ outof-plane vibrations and other modes [2,5-7]. These results can also be used to investigate mechanical and electrical anharmonicities of the vibrations, a topic that is incorporated into our research for the first time in the present work. With regard to the astrophysical context, it should be noted that we consider only neutral species in our studies; this contrasts with other investigations where both 
positive and negative ions were included in laboratory simulations of interstellar spectra [7-15]. For both hydrocarbon resource characterization and astrophysics applications, low wavenumber Raman and PA spectra may also permit identification of particular compounds or sub-molecular aromatic motifs in mixtures because at low wavenumbers spectra are less complex and bands are often linked to specific large-scale structures present in molecules, and specific molecular interactions. Concurrent experimental and computational evaluation of spectra for "families" of compounds provides a productive basis for gaining insights into both applications in general and into the identification of specific constituents in mixtures.

Raman and PA infrared spectra of fluorene $\left(\mathrm{C}_{13} \mathrm{H}_{10}\right.$; also known as $9 \mathrm{H}$-fluorene or diphenylenemethane), 2,3-benzofluorene $\left(\mathrm{C}_{17} \mathrm{H}_{12}\right)$, 2-methylfluorene $\left(\mathrm{C}_{14} \mathrm{H}_{12}\right)$, 2-ethylfluorene $\left(\mathrm{C}_{15} \mathrm{H}_{14}\right)$, and 1,8-dimethylfluorene $\left(\mathrm{C}_{15} \mathrm{H}_{14}\right)$ were acquired in the present work. Raman spectra were obtained in the wavenumber range from about 2000 to $100 \mathrm{~cm}^{-1}$, while far- and mid-infrared PA spectra together spanned the same region. Harmonic and anharmonic wavenumber calculations were also performed for these compounds. The observed Raman and infrared bands are correlated with calculated fundamental vibrations, or alternatively with predicted overtone and combination transitions, in this article. These results are expected to significantly enhance knowledge of the vibrational spectra of fluorene and its derivatives.

\section{Frequency calculations}

Calculations of frequencies and the corresponding intensities of large molecules according to harmonic theory are in general sufficiently reliable to enable analysis of the spectra and this strategy was employed in our earlier work $[1,2]$. Nevertheless, the results provided by the standard double-harmonic (mechanical and electrical) approximation are not sufficiently accurate for fine spectroscopic assignments. The appearance of combination and overtone bands in the PA spectra of aromatic hydrocarbons also shows that the harmonic approximation should be augmented by another approach. Accordingly, both harmonic (DFT) and anharmonic (variational) calculations were carried out in the present investigation.

\subsection{DFT method}

Fundamental frequencies were predicted at the B3LYP/6$311+G(d, p)$ level of theory as implemented in the Gaussian 09 suite of programs. Infrared and Raman frequencies and intensities were obtained in these calculations. Only results indicating energy minima with positive frequencies are reported. Basis sets were sufficiently large to ensure reasonable accuracies of the predicted frequencies. Calculated intensities were taken into consideration when correlating experimental data with the predicted bands for each compound.

\subsection{Variational method}

As mentioned above, the occurrence of combination and overtone bands in the hydrocarbon spectra indicates the anharmonic nature of the vibrations. Some authors scale their DFT-calculated frequencies to allow for anharmonicity and to obtain better agreement with the experimental data, even though this approach does not account for overtones or combination bands. Further the presence of anharmonic bands in the infrared spectra is a manifestation of the breakdown of the double-harmonic approximation. Since both mechanical (anharmonicity of the potential) and electrical (non-linear dependence of the dipole moment on the normal coordinates) anharmonicities are expected to give intensity to nonfundamental transitions, these two effects should be considered explicitly in the treatment of transition energies and related vibrational wavefunctions.

In this work frequency calculations were carried out in the mechanical and electrical anharmonic approximations, in the same process, using the variational method developed by Bégué et al. [16-20] and Baraille et al. [21], implemented in the P_Anhar.v2.0 program [22]. All vibrational frequencies (fundamentals, combination bands and overtones) that contribute to the infrared and Raman spectra, including those due to torsional motion, were computed. Calculations were performed for monomers and dimers of each compound.

\section{Experimental}

Fluorene, 2,3-benzofluorene, 2-methylfluorene, 2ethylfluorene and 1,8-dimethylfluorene were obtained from commercial sources at purity levels of at least $98 \%$ and analyzed as received. In some cases, samples were ground manually prior to acquisition of their spectra.

\subsection{Raman spectra}

Raman spectra were obtained using two spectrometers at CanmetENERGY (Devon, Alberta). In one set of experiments, a Renishaw InVia microscope-based system was coupled to a Spectra Physics $125 \mathrm{He}-\mathrm{Ne}$ laser, which provided excitation at $633 \mathrm{~nm}$. Several milligrams of each solid were examined with the use of a $50 \times$ microscope objective. Spectra were acquired with a spherically focused incident beam; typical resolution was better than $2 \mathrm{~cm}^{-1}$. Total accumulation time was $5 \mathrm{~min}$ for each spectrum. The other group of experiments was performed with a Bruker IFS 88 FT spectrometer and FRA 106 Raman accessory. Excitation of the FT-Raman spectra was effected with a 1064-nm Nd:YAG laser at power levels between 90 and $260 \mathrm{~mW}$. Ten 32-scan spectra with a resolution of $4 \mathrm{~cm}^{-1}$ were averaged for each sample.

\subsection{Far-infrared spectra}

PA far-infrared spectra were acquired at a resolution of $6 \mathrm{~cm}^{-1}$ using two different Bruker IFS 66v/S Fourier transform infrared (FT-IR) spectrometers. This resolution, which is somewhat lower than that utilized with other infrared techniques, was found to be adequate for the present study. Higher resolution yielded poorer signal-to-noise ratios and is unnecessary in view of the widths of the PA bands, which tend to be greater than those in the corresponding Raman spectra. The first instrument, at CanmetENERGY, was operated in both rapid- and step-scan modes. The He-Ne laser modulation frequency was $1.6 \mathrm{kHz}$ for the rapid-scan measurements, corresponding to the lowest scan velocity of this instrument. Large amplitude phase modulation [1] was employed in the stepscan experiments, with a Signal Recovery lock-in amplifier being utilized for demodulation. The second spectrometer was located at the Canadian Light Source (Saskatoon, Saskatchewan). Rapidscan spectra were acquired under conditions similar to those just mentioned. A thermal (globar) source was employed with this instrument.

Standard MTEC 300 gas-microphone PA accessories were used with both spectrometers; the sample cells were fitted with polyethylene windows. Helium was employed as the carrier gas. Multilayer mylar beamsplitters were installed in the interferometers. Spectra were recorded between about 700 and $50 \mathrm{~cm}^{-1}$, due to limits imposed by the optical materials. Carbon black powder or an MTEC carbon black reference yielded reference spectra that were 


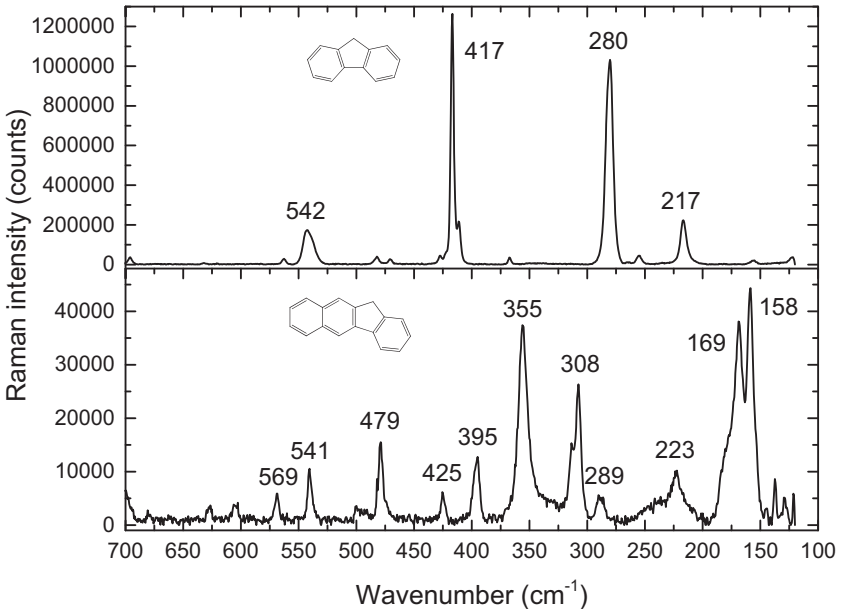

Fig. 1. Low wavenumber Raman spectra of fluorene (top panel) and 2,3benzofluorene (bottom panel).

used to correct sample spectra for the wavenumber-dependent response of each instrument.

\subsection{Mid-infrared spectra}

PA mid-infrared spectra were recorded at a resolution of $6 \mathrm{~cm}^{-1}$ using the Bruker IFS 88 spectrometer mentioned above. The laser frequency was either 1.6 or $2.2 \mathrm{kHz}$. An MTEC 200 PA cell was utilized. Nitrogen was used to purge the spectrometer and as a carrier gas. A $\mathrm{KBr}$ window sealed the PA cell, and a $\mathrm{Ge} / \mathrm{KBr}$ beamsplitter was used in the spectrometer. Ten 32-scan spectra were averaged for each sample. Spectra were acquired from about 4000 to $400 \mathrm{~cm}^{-1}$. Data are reported up to $2000 \mathrm{~cm}^{-1}$ in the body of this article. Data for the higher wavenumber region are summarized in the Supplementary material. Carbon black powder was used to obtain reference spectra in these experiments.

\section{Results and discussion}

Raman and PA infrared spectra of the five compounds studied in this work are discussed in the following two sections. The 'low wavenumber' ( $700-100 \mathrm{~cm}^{-1}$; commonly referred to as far infrared) and 'fingerprint' $\left(2000-700 \mathrm{~cm}^{-1}\right)$ regions are defined according to infrared spectroscopy convention. For convenience, the Raman and infrared data share the same demarcation limits, and are presented jointly in each section.

\subsection{Low wavenumber region $\left(\sim 700-100 \mathrm{~cm}^{-1}\right)$}

\subsubsection{Fluorene and 2,3-benzofluorene}

Raman spectra of fluorene and 2,3-benzofluorene (also known as $11 H$-benzo[ $b$ ]fluorene or isonaphthofluorene) are displayed in Fig. 1, with the corresponding PA infrared spectra appearing in Fig. 2. The predominance of the bands at 280 and $417 \mathrm{~cm}^{-1}$ in the Raman spectrum of fluorene (Fig. 1, upper curve) is a particularly noticeable result, as is the rather large number of bands in the PA spectra (Fig. 2). Tables 1 and 2 summarize band positions and relative intensities in the low wavenumber Raman and infrared spectra of both compounds, alongside the corresponding results from the harmonic and anharmonic calculations (including infrared intensities) performed in this work. Symmetry classifications for the fundamental modes are also given in these tables. Predicted frequencies and intensities for all modes, including those at higher wavenumbers, are listed in the Supplementary material.

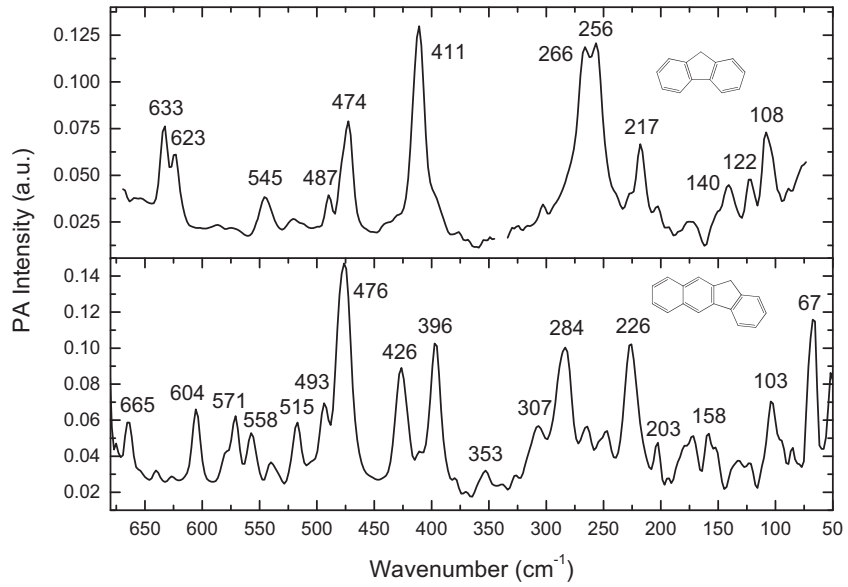

Fig. 2. Low wavenumber PA infrared spectra of fluorene (top panel) and 2,3benzofluorene (bottom panel). Spurious data near $340 \mathrm{~cm}^{-1}$ have been removed from the fluorene spectrum.

As discussed previously [2], the reported DFT calculations are not scaled. Consequently, the predicted values in column 3 of each table tend to be a few percent higher than their scaled counterparts (where these exist) in the literature. Scaling provides a correction (adjustment) for anharmonicity, but produces only small changes in the low wavenumber region. The discrepancies between predicted and observed frequencies are generally greater than these minor adjustments and there is no compelling reason to scale the DFT calculations. Treatment of anharmonicity using the variational method described in Section 2.2 is more appropriate. This method, which predicts fundamental, combination and overtone frequencies, as well as intensities, yielded the values reported in columns 4 and 5 of Tables 1 and 2. Several attributions to dimer vibrations are indicated in these tables and infrared- and Raman-active modes are denoted ' $d$ ' and 'Rd', respectively. Assignments to combinations and overtones, listed in column 5, provide interpretations of a number of weak features in the spectra. Correlations between the respective fundamental frequencies obtained via the DFT and variational methods (columns 3 and 4) for both compounds were generally straightforward. As predicted intensities were also considered during correlation development, two out-of-sequence pairs of close-lying frequencies in column 5 of Table 2 were identified.

\subsubsection{2-Methylfluorene, 2-ethylfluorene and \\ 1,8-dimethylfluorene}

Low wavenumber Raman spectra of three alkyl fluorene derivatives (2-methylfluorene, 2-ethylfluorene and 1,8dimethylfluorene) are shown in Fig. 3, while the PA infrared spectra are shown in Fig. 4. (Spurious features have been removed from two spectra in Figs. 2 and 4, producing small gaps in the data.) The Raman spectra are presented using greatly different intensity scales, as is mandated by the diverse intensities observed for these three substances in this region. The recorded spectrum for 2-ethylfluorene is from one to two orders of magnitude weaker than those of the two other compounds, probably because of the very small quantity of 2-ethylfluorene available for analysis. By contrast, PA intensities in the infrared spectra of the three alkyl derivatives are not disparate (Fig. 4). The PA spectra for these compounds are not reported below $200 \mathrm{~cm}^{-1}$ to avoid artifacts and noise arising in this region. Despite this limitation, the Raman and PA infrared spectra in Figs. 3 and 4 comprise some of the first known low wavenumber data for these compounds.

Tables 3-5 list the wavenumbers and relative intensities of the observed bands for 2-methylfluorene, 2-ethylfluorene and 1,8-dimethylfluorene, respectively. Symmetry classifications are 
Table 1

Low wavenumber Raman and PA infrared spectra of fluorene $\left(C_{2 v}\right)$.

\begin{tabular}{|c|c|c|c|c|c|}
\hline \multicolumn{2}{|c|}{ Observed } & \multicolumn{4}{|l|}{ Predicted $^{\mathrm{a}}$} \\
\hline $\operatorname{Raman}^{\mathrm{b}}$ & Infrared $^{\mathrm{b}}$ & Symmetry & Harmonic $^{c}$ & Anharmonic $^{\mathrm{d}}$ & Combination $^{\mathrm{d}}$ \\
\hline \multirow[t]{5}{*}{696 vw } & $697 \mathrm{~s}$ & $\mathrm{~b}_{1}$ & $710(5.4)$ & $713(2.9)$ & \\
\hline & & & & $710(0.1)$ & $277+433$ \\
\hline & & & & $693(0.1)$ & $140+580$ \\
\hline & $667 \mathrm{sh}$ & & & $664(0.6)$ & $248+416$ \\
\hline & $650 \mathrm{vw}$ & & & $654(0.1)$ & $99+558$ \\
\hline \multirow[t]{4}{*}{632 vw } & $633 \mathrm{w}$ & $a_{1}$ & $645(0.3)$ & $650(0.5)^{\mathrm{e}}$ & \\
\hline & $623 w$ & $\mathrm{~b}_{2}$ & $636(7.7)$ & $645(8.1)$ & \\
\hline & $587 \mathrm{vw}$ & & & & \\
\hline & $573 \mathrm{vw}$ & $a_{2}$ & $574(0.0)$ & $580(0.0)$ & \\
\hline $562 \mathrm{vw}$ & & & & $571 \mathrm{Rd}$ & \\
\hline \multirow[t]{3}{*}{$542 \mathrm{~m}$} & $545 \mathrm{w}$ & $\mathrm{b}_{2}$ & $553(0.1)$ & $558(0.1)$ & \\
\hline & & & & $546(0.1)^{f}$ & $140+433$ \\
\hline & $519 \mathrm{w}$ & & & & \\
\hline $482 \mathrm{vw}$ & $487 w$ & $\mathrm{~b}_{2}$ & $498(0.3)$ & $498(0.4)$ & \\
\hline $471 \mathrm{vw}$ & $474 \mathrm{~m}$ & $\mathrm{~b}_{1}$ & $479(0.8)$ & $488(2.0)$ & \\
\hline $427 \mathrm{sh}$ & $428 \mathrm{sh}$ & $a_{2}$ & $437(0.0)$ & $433(0.0)$ & \\
\hline $417 \mathrm{~s}$ & & $a_{1}$ & $419(0.4)$ & $420(0.3)$ & \\
\hline $411 \mathrm{sh}$ & $411 \mathrm{~s}$ & $\mathrm{~b}_{1}$ & $421(6.2)$ & 416 (7.2), $429 \mathrm{Rd}$ & \\
\hline \multirow[t]{2}{*}{367 vw } & & & & $362(1.2)$ & $140+248$ \\
\hline & $302 \mathrm{w}$ & & & & \\
\hline \multirow[t]{2}{*}{$280 \mathrm{~s}$} & & $a_{2}$ & $273(0.0)$ & $277(0.0)$ & \\
\hline & $266 \mathrm{~m}$ & & & & \\
\hline $255 \mathrm{vw}$ & $256 \mathrm{~m}$ & $\mathrm{~b}_{1}$ & $240(7.3)$ & $248(8.0)$ & \\
\hline \multirow[t]{2}{*}{$217 \mathrm{~m}$} & $217 \mathrm{~m}$ & $a_{1}$ & $217(0.2)$ & $211(0.2), 221 \mathrm{~d}$ & \\
\hline & $172 \mathrm{w}$ & & & & \\
\hline \multirow[t]{4}{*}{$156 \mathrm{vw}$} & $151 \mathrm{vw}$ & & & $157 \mathrm{~d}$ & \\
\hline & $140 \mathrm{w}$ & $a_{2}$ & $136(0.0)$ & $140(0.0)$ & \\
\hline & $122 \mathrm{w}$ & & & & \\
\hline & $108 \mathrm{~m}$ & $b_{1}$ & $98(0.6)$ & $99(0.7)$ & \\
\hline
\end{tabular}

a Infrared intensities (in parentheses) in $\mathrm{km} / \mathrm{mol}$.

b Estimated uncertainties in band positions are within $\pm 3 \mathrm{~cm}^{-1}$. Relative intensities: vw $=$ very weak, $\mathrm{w}=$ weak, $\mathrm{m}=\mathrm{medium}, \mathrm{s}=\mathrm{strong}, \mathrm{vs}=\mathrm{very}$ strong, sh $=\mathrm{shoulder}$

c Unscaled DFT frequencies calculated using B3LYP/6-311+G(d,p) as described elsewhere [3].

d Anharmonics B3LYP/6-311 calculation using the $\mathrm{P}_{-} \mathrm{VMWCI}_{2}$ algorithm [21,22]. $\mathrm{d}=$ infrared-active dimer vibration, $\mathrm{Rd}=\mathrm{Raman}$-active dimer vibration.

e Eigenvector contains $10 \%$ contribution from $416+211 \mathrm{~cm}^{-1}$ combination.

f Eigenvector contains $12 \%$ contribution from $416+99 \mathrm{~cm}^{-1}$ combination.

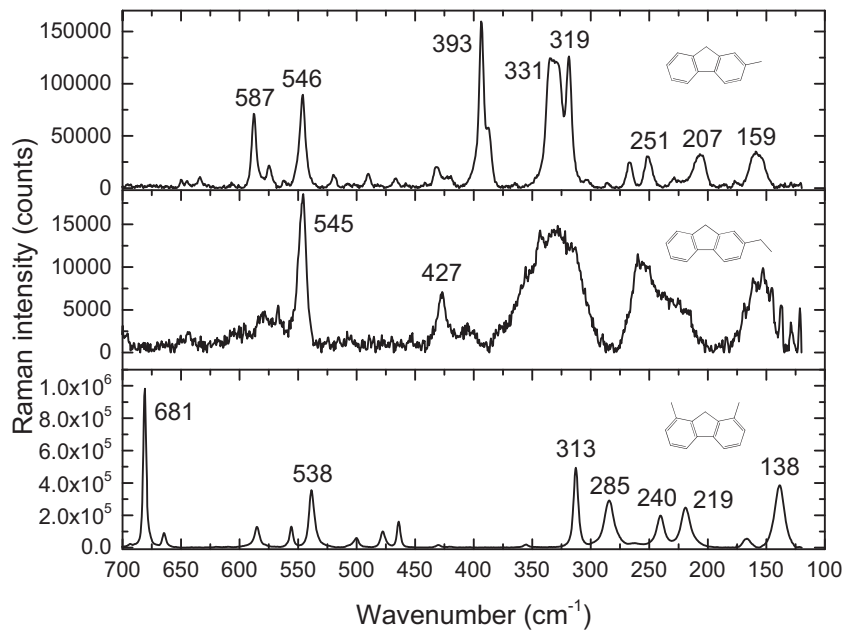

Fig. 3. Low wavenumber Raman spectra of 2-methylfluorene (top panel), 2ethylfluorene (middle panel) and 1,8-dimethylfluorene (bottom panel).

included for 1,8-dimethylfluorene in column 3 of Table 5 . The lower symmetries of 2-methylfluorene and 2-ethylfluorene $\left(\mathrm{C}_{1}\right)$ obviate the need for comparable classifications in Tables 3 and 4 . Predicted harmonic and anharmonic frequencies are given in each table according to the convention established for Tables 1 and 2. The anharmonic calculations yielded several dimer vibrations, as well as combinations and overtones (columns 4 and 5). Both intensities and wavenumbers obtained in the harmonic and variational calculations were taken into account as the individual bands in

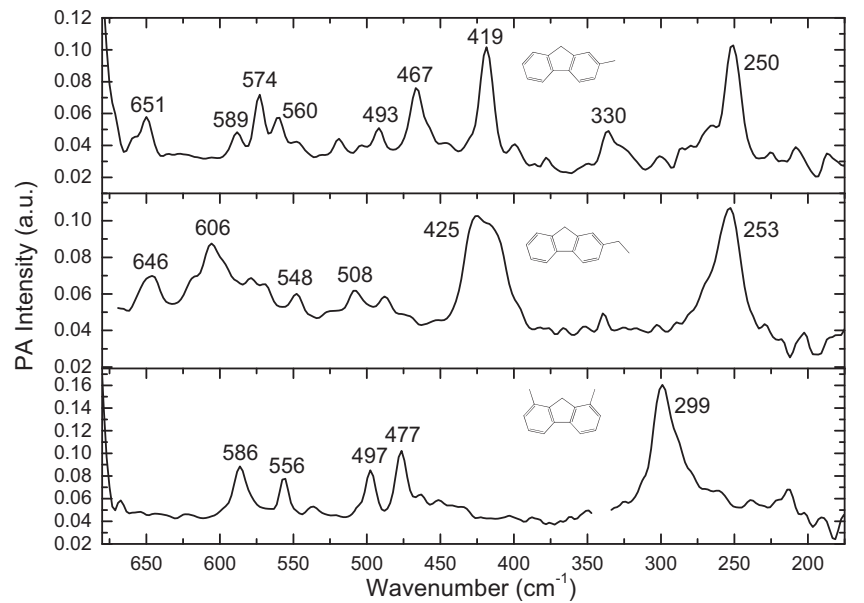

Fig. 4. Low wavenumber PA infrared spectra of 2-methylfluorene (top panel), 2 ethylfluorene (middle panel) and 1,8-dimethylfluorene (bottom panel). Spurious data near $340 \mathrm{~cm}^{-1}$ have been removed from the 1,8-dimethylfluorene spectrum.

the Raman and infrared spectra were correlated with the predictions. As is the case for fluorene and 2,3-benzofluorene, the low wavenumber Raman and PA infrared spectra of the alkylsubstituted fluorenes contain much detail; sufficient information for the identification and characterization of these compounds.

The lowest calculated fundamental frequencies for 2methylfluorene in Table 3 (harmonic, $24 \mathrm{~cm}^{-1}$; anharmonic, $20 \mathrm{~cm}^{-1}$ ) lie beyond the low wavenumber cutoff of the mylar beamsplitters used for the far-infrared measurements. Attempts 
Table 2

Low wavenumber Raman and PA infrared spectra of 2,3-benzofluorene $\left(C_{S}\right)$.

\begin{tabular}{|c|c|c|c|c|c|}
\hline \multicolumn{2}{|c|}{ Observed } & \multicolumn{4}{|l|}{ Predicted $^{\mathrm{a}}$} \\
\hline Raman $^{\text {b }}$ & $\overline{\text { Infrared }^{\mathrm{b}}}$ & Symmetry & Harmonic $^{c}$ & Anharmonic $^{\mathrm{d}}$ & Combination or overtone $^{\mathrm{d}}$ \\
\hline \multirow{3}{*}{$\begin{array}{l}700 \mathrm{w} \\
680 \mathrm{vw}\end{array}$} & $700 \mathrm{sh}$ & $a^{\prime}$ & $713(2.1)$ & $719(1.4)$ & \\
\hline & $665 \mathrm{w}$ & $a^{\prime \prime}$ & $677(0.7)$ & $683(1.5)$ & \\
\hline & $640 \mathrm{vw}$ & $a^{\prime}$ & $644(0.1)$ & $654(0.1)$ & \\
\hline $627 \mathrm{vw}$ & $626 \mathrm{vw}$ & $a^{\prime}$ & $617(2.4)$ & $627(0.7)$ & \\
\hline $605 \mathrm{vw}$ & $604 \mathrm{w}$ & $a^{\prime}$ & $582(8.6)$ & $589(7.2)$ & \\
\hline \multirow[t]{2}{*}{569 w } & $571 \mathrm{w}$ & $a^{\prime \prime}$ & $564(0.3)$ & $573(0.3)$ & \\
\hline & $558 \mathrm{w}$ & $a^{\prime}$ & $549(1.0)$ & $553(0.7)$ & \\
\hline \multirow[t]{3}{*}{$541 \mathrm{~m}$} & $540 \mathrm{vw}$ & & & & $62+498$ \\
\hline & 515 w & $a^{\prime \prime}$ & $501(0.1)$ & $510(0.1)$ & \\
\hline & $493 \mathrm{~m}$ & $a^{\prime}$ & $490(0.4)$ & $498(0.2)^{\mathrm{e}}$ & \\
\hline $479 \mathrm{~m}$ & $476 \mathrm{~s}$ & $a^{\prime \prime}$ & $483(16.7)$ & $487(16.4)$ & \\
\hline \multirow[t]{2}{*}{$425 \mathrm{w}$} & $426 \mathrm{~m}$ & $a^{\prime \prime}$ & $435(1.4)$ & $437(2.0)$ & \\
\hline & & & & $427(0.2)$ & $2 \times 213$ \\
\hline 395 m & $396 \mathrm{~m}$ & $a^{\prime \prime}$ & $405(3.1)$ & $408(3.2)^{f}$ & \\
\hline $355 \mathrm{~s}$ & $353 \mathrm{w}$ & $a^{\prime}$ & $357(0.1)$ & $359(0.1)$ & \\
\hline $314 \mathrm{sh}$ & & $a^{\prime \prime}$ & $312(0.2)$ & $312(0.1)$ & \\
\hline $308 \mathrm{~m}$ & 307 w & $a^{\prime}$ & $312(0.7)$ & $315(0.6)$ & \\
\hline \multirow[t]{3}{*}{$289 \mathrm{w}$} & $284 \mathrm{~m}$ & $a^{\prime \prime}$ & $272(2.9)$ & $281(3.2)$ & \\
\hline & $265 \mathrm{w}$ & & & & \\
\hline & $248 \mathrm{w}$ & & & $255(0.2)$ & $94+213$ \\
\hline \multirow[t]{2}{*}{$223 \mathrm{~m}$} & $226 \mathrm{~m}$ & & & $239(0.1)$ & $94+156$ \\
\hline & $203 \mathrm{w}$ & $a^{\prime \prime}$ & $206(2.3)$ & $213(2.0)$ & \\
\hline $169 \mathrm{~s}$ & $172 \mathrm{w}$ & & & $161(0.1)$ & $62+94$ \\
\hline \multirow[t]{2}{*}{$158 \mathrm{~s}$} & $158 \mathrm{w}$ & $a^{\prime}$ & $156(0.1)$ & $156(0.5)$ & \\
\hline & $152 \mathrm{sh}$ & $a^{\prime \prime}$ & $155(0.6)$ & $158(0.1)$ & \\
\hline \multicolumn{6}{|l|}{$144 \mathrm{vw}$} \\
\hline $138 \mathrm{w}$ & $133 \mathrm{w}$ & & & $139 \mathrm{~d}$ & \\
\hline \multirow[t]{3}{*}{$129 \mathrm{w}$} & $122 \mathrm{w}$ & & & $123(0.1)$ & $2 \times 62$ \\
\hline & $103 \mathrm{~m}$ & $a^{\prime \prime}$ & $95(0.2)$ & $94(0.1)$ & \\
\hline & $67 \mathrm{~m}$ & $a^{\prime \prime}$ & $62(0.5)$ & $62(0.5)$ & \\
\hline
\end{tabular}

a Infrared intensities (in parentheses) in $\mathrm{km} / \mathrm{mol}$.

b Estimated uncertainties in band positions are within $\pm 3 \mathrm{~cm}^{-1}$. Relative intensities: $\mathrm{vw}=$ very weak, $\mathrm{w}=\mathrm{weak}, \mathrm{m}=\mathrm{medium}, \mathrm{s}=\mathrm{strong}, \mathrm{vs}=\mathrm{very}$ strong, sh $=\mathrm{shoulder}$

c Unscaled DFT frequencies calculated using B3LYP/6-311+G(d,p) as described elsewhere [3].

d Anharmonics B3LYP/6-311 calculation using the $\mathrm{P}_{-} \mathrm{VMWCI}_{2}$ algorithm [21,22]. $\mathrm{d}=$ infrared-active dimer vibration.

e Eigenvector contains $9 \%$ contribution from $281+213 \mathrm{~cm}^{-1}$ combination.

${ }^{f}$ Eigenvector contains $5 \%$ contribution from $804 \mathrm{~cm}^{-1}$ mode.

are currently underway to study this region in separate experiments at the Canadian Light Source. This work entails the use of coherent synchrotron radiation [23] in place of a conventional optical source for PA infrared spectroscopy. The currently accessible region in this experiment [24], which employs a Bruker IFS 125HR spectrometer and a different beamsplitter, extends from about 5 to $25 \mathrm{~cm}^{-1}$. Initial experiments have produced inconclusive results but this investigation is ongoing.

\subsection{Fingerprint region $\left(2000-700 \mathrm{~cm}^{-1}\right)$}

\subsubsection{Fluorene and 2,3-benzofluorene}

The $2000-700 \mathrm{~cm}^{-1}$ regions of the observed Raman and PA spectra for fluorene and 2,3-benzofluorene are shown in Figs. 5 and 6, respectively. Several noteworthy aspects of these spectra are immediately apparent. These include (a) very good band definition and contrast in the Raman spectra; (b) significantly greater bandwidths and the absence of void regions in the PA infrared spectra; and (c) prominent overtone and combination bands above $1640 \mathrm{~cm}^{-1}$ in both PA spectra. Comparison of the upper and lower panels in Fig. 5 also reveals a few near-coincidences of Raman bands for the two compounds, consistent with their structural similarity.

Band positions and relative intensities in Figs. 5 and 6 for the experimental measurements and the calculations are summarized in Table 6 (fluorene) and 7 (2,3-benzofluorene). The predicted wavenumbers appear in columns 3 and 4 of these tables, regardless of the presence or absence of corresponding bands in the measured spectra and they were interpreted in the same manner as the low wavenumber calculations. Most of the combinations and overtones

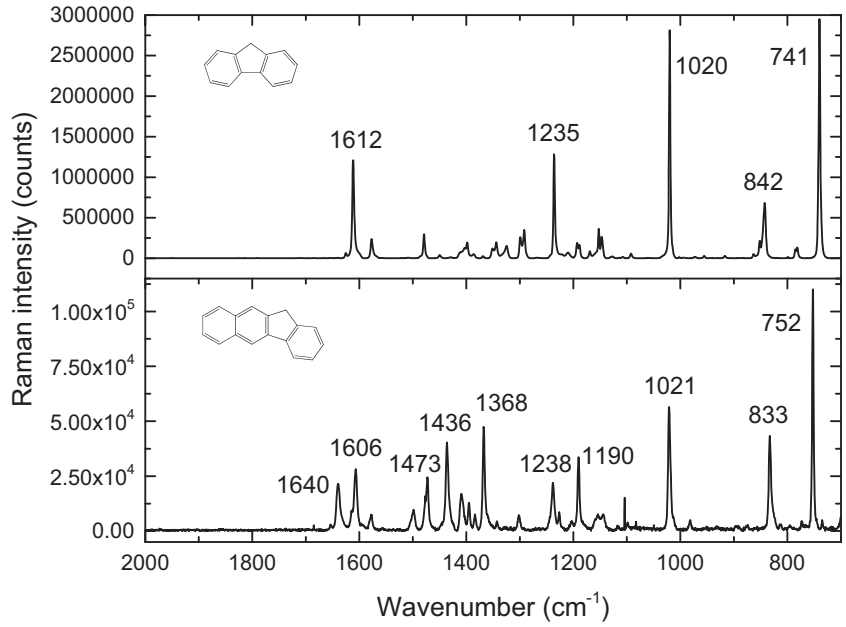

Fig. 5. Fingerprint region Raman spectra of fluorene (top panel) and 2,3benzofluorene (bottom panel).

at higher wavenumbers in the infrared spectra are predicted in the variational calculations. Minor unassigned bands in both the Raman and PA spectra presumably have analogous origins.

The assignments of the combination and overtone bands above $1640 \mathrm{~cm}^{-1}$ in the PA infrared spectra deserve further comment. Tables 6 and 7 show that these attributions involve mediumor strong-intensity bands between about 1100 and $700 \mathrm{~cm}^{-1}$ for the most part. The DFT and anharmonic calculations confirm 
Table 3

Low wavenumber Raman and PA infrared spectra of 2-methylfluorene $\left(C_{1}\right)$.

\begin{tabular}{|c|c|c|c|c|}
\hline \multicolumn{2}{|c|}{ Observed } & \multicolumn{3}{|l|}{ Predicted $^{\mathrm{a}}$} \\
\hline Raman $^{\mathrm{b}}$ & Infrared $^{\mathrm{b}}$ & Harmonic $^{\mathrm{c}}$ & Anharmonic ${ }^{\mathrm{d}}$ & Combination or overtone ${ }^{\mathrm{d}}$ \\
\hline & $675 \mathrm{~m}$ & $658(1.4)$ & $660(0.5)$ & \\
\hline $650 \mathrm{vw}$ & $651 \mathrm{~m}$ & & & $69+591$ \\
\hline \multirow{2}{*}{\multicolumn{5}{|c|}{$\begin{array}{l}644 \mathrm{vw} \\
634 \mathrm{vw}\end{array}$}} \\
\hline & \multicolumn{4}{|c|}{$634 \mathrm{vw}$} \\
\hline & $618 \mathrm{vw}$ & & & \\
\hline \multicolumn{5}{|l|}{$607 \mathrm{vw}$} \\
\hline $587 \mathrm{w}$ & $589 \mathrm{sh}$ & & & \\
\hline 575 vw & $574 \mathrm{~m}$ & $586(2.4)$ & $591(1.7)$ & \\
\hline $562 \mathrm{vw}$ & $560 \mathrm{vw}$ & $582(2.1)$ & $589(2.0)$ & \\
\hline $546 \mathrm{~m}$ & $546 \mathrm{vw}$ & $555(0.9)$ & $560(0.5)$ & \\
\hline 520 vw & $518 \mathrm{vw}$ & $512(0.4)$ & $516(0.3)$ & \\
\hline 490 vw & $493 \mathrm{vw}$ & $499(0.7)$ & $506(0.3)^{e}$ & $2 \times 250$ \\
\hline 467 vw & $467 \mathrm{~m}$ & & & \\
\hline $432 \mathrm{vw}$ & & $436(0.2)$ & $437(0.1)$ & \\
\hline $421 \mathrm{vw}$ & $419 \mathrm{~m}$ & $426(9.0)$ & $434(6.1)^{f}$ & \\
\hline $393 \mathrm{~m}$ & $395 \mathrm{vw}$ & $397(0.2)$ & $398(0.2)$ & \\
\hline \multicolumn{5}{|l|}{$387 \mathrm{sh}$} \\
\hline \multicolumn{5}{|l|}{365 vw } \\
\hline $331 \mathrm{~m}$ & $330 \mathrm{w}$ & $327(0.9)$ & $331(0.2)$ & \\
\hline $319 \mathrm{~m}$ & & $319(0.1)$ & $319(0.1)$ & \\
\hline 304 vw & $303 \mathrm{vw}$ & & & \\
\hline 286 vw & $285 \mathrm{sh}$ & & & \\
\hline $267 \mathrm{w}$ & & & $270 \mathrm{Rd}$ & \\
\hline $251 \mathrm{w}$ & $250 \mathrm{~m}$ & $240(6.8)$ & $250(3.0)$ & \\
\hline 229 vw & $226 \mathrm{vw}$ & & & \\
\hline 207 w & $206 \mathrm{vw}$ & $194(0.3)$ & $198(0.4)$ & \\
\hline 177 vw & & $185(0.4)$ & $183(0.1)$ & \\
\hline \multirow[t]{4}{*}{$159 \mathrm{w}$} & & & $142(0.1)$ & $20+132$ \\
\hline & & $134(0.1)$ & $132(0.1)$ & \\
\hline & & $72(0.6)$ & $69(0.3)$ & \\
\hline & & $24(0.3)$ & $20(0.2)$ & \\
\hline
\end{tabular}

a Infrared intensities (in parentheses) in $\mathrm{km} / \mathrm{mol}$.

b Estimated uncertainties in band positions are within $\pm 3 \mathrm{~cm}^{-1}$. Relative intensities: vw $=$ very weak, $\mathrm{w}=\mathrm{weak}, \mathrm{m}=\mathrm{medium}, \mathrm{s}=\mathrm{strong}, \mathrm{vs}=\mathrm{very} \mathrm{strong}$, sh $=\mathrm{shoulder}$.

c Unscaled DFT frequencies calculated using B3LYP/6-311+G(d,p) as described elsewhere [3].

d Anharmonics B3LYP/6-311 calculation using the $\mathrm{P}_{-} \mathrm{VMWCI}_{2}$ algorithm [21,22]. Rd = Raman-active dimer vibration.

e Eigenvector contains $7 \%$ contribution from $3 \times 250 \mathrm{~cm}^{-1}$ overtone.

${ }^{\mathrm{f}}$ Eigenvector contains $6 \%$ contribution from $250+132 \mathrm{~cm}^{-1}$ combination.

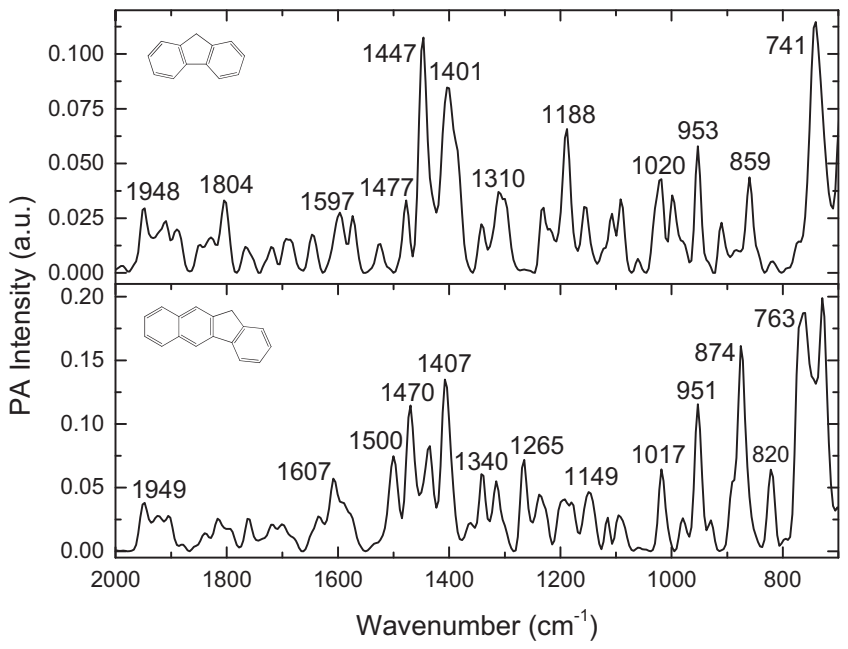

Fig. 6. Fingerprint region PA infrared spectra of fluorene (top panel) and 2,3benzofluorene (bottom panel).

that many of these bands arise from $\mathrm{a}_{2}$ and $\mathrm{b}_{1}$ (fluorene; $C_{2 v}$ symmetry) or a" (2,3-benzofluorene; $C_{s}$ symmetry) modes. The vibrations implicated below $\sim 1000 \mathrm{~cm}^{-1}$ generally entail outof-plane displacement of carbon-carbon and carbon-hydrogen groups. Combination bands in the $2000-1640 \mathrm{~cm}^{-1}$ region involving non-planar $\mathrm{CH}$ vibrations have been reported previously
[2,5-7]. Hence this aspect of the present work is consistent with previously published literature.

Spectral data for fluorene also provide points of contact with the analytical [25-28] and applied [29-32] literatures. Infrared [25-28] and Raman [26-28] spectra for fluorene are available. The single crystal study of Bree and Zwarich [26] is particularly informative. UV-excited Raman spectra of fluorene were reported by Asher and coworkers as part of their studies of coal liquids [29,30]. Similarly, Chua and Stair discussed UV Raman spectra of fluorene and several polyaromatic compounds in an investigation of methanol-to-hydrocarbons conversion [31]. Raman spectra of fluorene adsorbed on $\mathrm{TiO}_{2}$ were obtained as part of a photocatalytic study by Cordeiro and Corio [32]. The band locations in these publications generally agree with their counterparts in columns 1 and 2 of Tables 1 and 6, although the relative intensities differ in some cases due to the diverse experimental conditions employed in these works. A recent publication on gas phase infrared spectra of fluorene, 1-methylfluorene and 1,8-dimethylfluorene [33] reports both harmonic and anharmonic calculated frequencies, the former agreeing with the present results to within $\pm 2 \mathrm{~cm}^{-1}$ in most cases. The anharmonic frequencies in their work were fitted to gas phase data, and thus show much poorer agreement with the values computed in this work.

For 2,3-benzofluorene an experimental infrared and DFT investigation of neutral and cationic 2,3-benzofluorene [34] is available for comparison. This article reports calculated frequencies for most, but not all, infrared-active fundamentals. These frequencies, which are scaled, are generally similar to the respective anharmonic frequencies reported in column 5 of Table 7. 
Table 4

Low wavenumber Raman and PA infrared spectra of 2-ethylfluorene $\left(C_{1}\right)$.

\begin{tabular}{|c|c|c|c|c|}
\hline \multicolumn{2}{|c|}{ Observed } & \multicolumn{3}{|l|}{ Predicted $^{\mathrm{a}}$} \\
\hline $\operatorname{Raman}^{\mathrm{b}}$ & Infrared $^{\mathrm{b}}$ & Harmonic $^{c}$ & Anharmonic $^{\mathrm{d}}$ & Combination or overtone $^{\mathrm{d}}$ \\
\hline & $646 \mathrm{~m}$ & $657(1.6)$ & $664(1.6)$ & \\
\hline & $606 \mathrm{~m}$ & $619(4.4)$ & $626(4.0)$ & \\
\hline 580 vw & $578 \mathrm{vw}$ & & & \\
\hline 567 vw & $569 \mathrm{sh}$ & $578(1.7)$ & $575(1.1)^{\mathrm{e}}$ & \\
\hline \multirow[t]{3}{*}{$545 w$} & $548 w$ & $554(0.7)$ & $561(0.5)$ & \\
\hline & $525 \mathrm{sh}$ & $517(1.0)$ & $529(0.4)$ & \\
\hline & & $512(0.6)$ & $519(0.6)$ & \\
\hline \multirow[t]{2}{*}{$505 \mathrm{vw}$} & $508 \mathrm{w}$ & & $503(0.1)$ & $247+259$ \\
\hline & $487 w$ & & $493(0.5)^{\mathrm{f}}$ & $2 \times 247$ \\
\hline \multirow[t]{2}{*}{$454 \mathrm{vw}$} & & & $460 \mathrm{Rd}$ & \\
\hline & & $437(0.6)$ & $441(1.2)$ & \\
\hline \multirow[t]{2}{*}{$427 w$} & $425 \mathrm{~s}$ & $434(6.2)$ & $443(5.8)$ & \\
\hline & $416 \mathrm{sh}$ & & & \\
\hline $404 \mathrm{vw}$ & & $410(1.8)$ & $409(1.2)$ & \\
\hline 343 vw & $340 \mathrm{vw}$ & $367(0.1)$ & $374(0.1)$ & \\
\hline \multirow[t]{2}{*}{330 vw } & & $327(0.2)$ & $330(0.2)$ & \\
\hline & & $258(0.2)$ & $259(0.2)$ & \\
\hline $255 \mathrm{vw}$ & $253 \mathrm{~s}$ & $240(6.7)$ & $247(7.1)$ & \\
\hline $226 \mathrm{vw}$ & & $229(0.1)$ & $215(0.1)$ & \\
\hline 169 vw & $172 \mathrm{w}$ & $174(0.2)$ & $175(0.2)$ & \\
\hline $152 \mathrm{vw}$ & & $148(0.1)$ & $151(0.1)$ & \\
\hline $145 \mathrm{vw}$ & & & $148 \mathrm{Rd}$ & \\
\hline \multicolumn{5}{|l|}{$138 \mathrm{vw}$} \\
\hline \multirow[t]{3}{*}{$129 \mathrm{vw}$} & & $129(0.1)$ & $130(0.1)$ & \\
\hline & & $58(0.4)$ & $57(0.3)$ & \\
\hline & & $34(0.1)$ & $32(0.1)$ & \\
\hline
\end{tabular}

a Infrared intensities (in parentheses) in $\mathrm{km} / \mathrm{mol}$.

b Estimated uncertainties in band positions are within $\pm 3 \mathrm{~cm}^{-1}$. Relative intensities: $\mathrm{vw}=$ very weak, $\mathrm{w}=\mathrm{weak}, \mathrm{m}=\mathrm{medium}, \mathrm{s}=\mathrm{strong}, \mathrm{vs}=\mathrm{very} \mathrm{strong}, \mathrm{sh}=\mathrm{shoulder}$.

c Unscaled DFT frequencies calculated using B3LYP/6-311+G(d,p) as described elsewhere [3].

d Anharmonics B3LYP/6-311 calculation using the $\mathrm{P}_{-} \mathrm{VMWCI}_{2}$ algorithm $[21,22]$. Rd = Raman-active dimer vibration.

e Eigenvector contains $8 \%$ contribution from $330+247 \mathrm{~cm}^{-1}$ combination.

${ }^{\mathrm{f}}$ Eigenvector contains $6 \%$ contribution from $3 \times 247 \mathrm{~cm}^{-1}$ overtone and $5 \%$ contribution from $247 \mathrm{~cm}^{-1}$ mode.

The $1075-990 \mathrm{~cm}^{-1}$ region of the PA infrared spectra of fluorene and 2,3-benzofluorene was also examined in our laboratory using a quantum cascade laser (QCL) as the infrared radiation source. Laser-based PA infrared spectra typically display much narrower bands than those in FT-IR spectra [35,36], often facilitating observation of shoulders and detection of weak bands. This brief study suggested probable new features at approximately 994, 996 and $1032 \mathrm{~cm}^{-1}$ for fluorene, the two lower frequency bands possibly corresponding to similar calculated frequencies in columns 4 and 5 of Table 6 . The 2,3-benzofluorene spectrum displayed bands at 1017 and $1021 \mathrm{~cm}^{-1}$, the latter feature being revealed due to reduced band widths. Hence additional useful information was acquired in the QCL experiment, despite the narrow range of the measurements.

\subsubsection{2-Methylfluorene, 2-ethylfluorene and 1,8-dimethylfluorene}

The fingerprint regions of the Raman and PA spectra obtained for the alkyl derivatives of fluorene are shown in Figs. 7 and 8, respectively. The Raman spectra display a number of well-defined bands, with intensities ranging over multiple orders of magnitude. By contrast the PA infrared spectra exhibit characteristically wider bands, which occur within a much smaller dynamic range. As noted in the previous section, the PA spectra include an appreciable number of bands throughout the entire $2000-700 \mathrm{~cm}^{-1}$ region, while the Raman spectra do not contain significant features above approximately $1750 \mathrm{~cm}^{-1}$.

Experimental and computed wavenumbers and intensities for the alkylated fluorenes are reported in Tables 8-10. No previously published calculations are known for these compounds. Correlations between the observed and calculated bands were developed using both position and intensity information, the majority of these assignments being relatively straightforward. Nevertheless, the

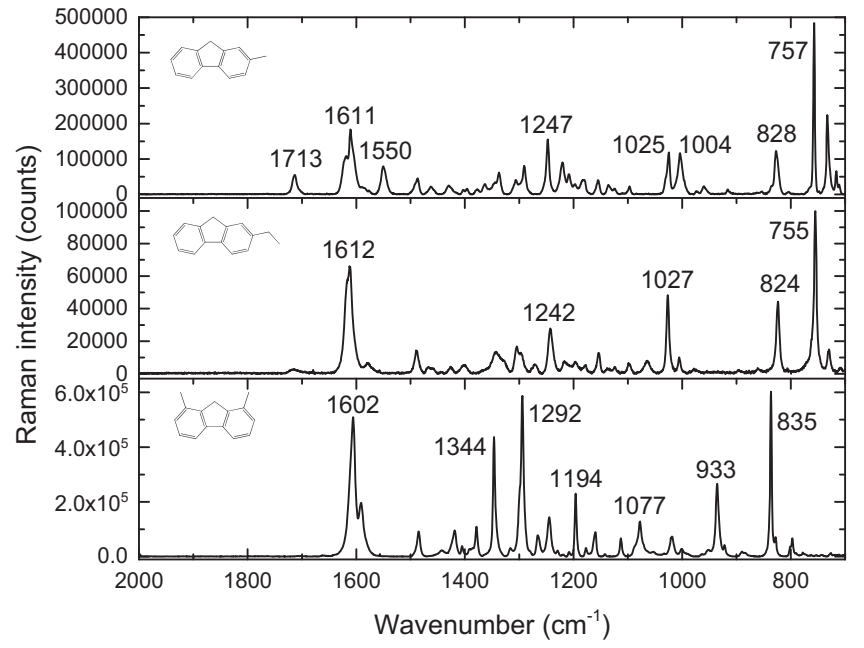

Fig. 7. Fingerprint region Raman spectra of 2-methylfluorene (top panel), 2ethylfluorene (middle panel) and 1,8-dimethylfluorene (bottom panel).

existence of large numbers of fundamentals for the substituted compounds inevitably leads to a few ambiguities. Additionally, there is a tendency for neighboring vibrations to occur very close to one another in particular regions (e.g., $\sim 1500$ and $\sim 1600 \mathrm{~cm}^{-1}$ ). More bands may be calculated than observed in some cases, implying that it is not always feasible to make definitive assignments. Again, all predicted frequencies appear in the tables, irrespective of the number of bands actually observed in the spectra.

These tables also present a number of assignments to combinations and overtones of infrared-active vibrations between $\sim 1500$ and $700 \mathrm{~cm}^{-1}$. Calculated anharmonic frequencies were used for these attributions, often leading to predicted frequencies slightly 
Table 5

Low wavenumber Raman and PA infrared spectra of 1,8-dimethylfluorene $\left(C_{2 v}\right)$.

\begin{tabular}{|c|c|c|c|c|c|}
\hline \multicolumn{2}{|c|}{ Observed } & \multicolumn{4}{|l|}{ Predicted $^{\mathrm{a}}$} \\
\hline Raman $^{b}$ & Infrared $^{\mathrm{b}}$ & Symmetry & Harmonic $^{\mathrm{c}}$ & Anharmonic ${ }^{\mathrm{d}}$ & Combination $^{d}$ \\
\hline $694 \mathrm{vw}$ & $693 \mathrm{~m}$ & $\mathrm{~b}_{1}$ & $709(8.5)$ & $699(4.2)$ & \\
\hline 681 vs & & $a_{1}$ & $692(0.1)$ & $692(0.2)$ & \\
\hline \multirow[t]{4}{*}{$664 \mathrm{w}$} & $668 \mathrm{vw}$ & & & & \\
\hline & $645 \mathrm{vw}$ & & & $650(0.1)$ & $113+543$ \\
\hline & $622 \mathrm{vw}$ & & & $616(0.2)$ & $113+506$ \\
\hline & & $\mathrm{a}_{2}$ & $599(0.0)$ & $589(0.0)$ & \\
\hline \multirow{2}{*}{$585 \mathrm{w}$} & $586 \mathrm{~m}$ & $\mathrm{~b}_{2}$ & $594(4.3)$ & $598(3.6)$ & \\
\hline & $556 \mathrm{~m}$ & $\mathrm{~b}_{2}$ & $566(3.0)$ & $571(3.3)$ & \\
\hline \multirow[t]{2}{*}{$538 \mathrm{~m}$} & $536 \mathrm{w}$ & $a_{1}$ & $544(0.6)$ & $543(0.4)$ & \\
\hline & & $\mathrm{b}_{1}$ & $511(1.0)$ & $513(0.9)$ & \\
\hline $500 \mathrm{~m}$ & $497 \mathrm{~m}$ & $\mathrm{a}_{2}$ & $510(0.0)$ & $506(0.0)$ & \\
\hline $478 w$ & $477 \mathrm{~m}$ & $\mathrm{~b}_{2}$ & $485(0.2)$ & $481(1.1)$ & \\
\hline \multirow[t]{3}{*}{$464 \mathrm{w}$} & $464 \mathrm{vw}$ & $\mathrm{b}_{1}$ & $481(0.3)$ & $476(0.1)^{\mathrm{e}}$ & \\
\hline & & $a_{1}$ & $468(0.4)$ & $460(0.2)^{\mathrm{f}}$ & \\
\hline & $451 \mathrm{vw}$ & & & $460(0.1)$ & $147+316$ \\
\hline \multirow[t]{3}{*}{$430 \mathrm{vw}$} & & & & $431(0.2)$ & $147+286$ \\
\hline & $403 \mathrm{vw}$ & & & $397(0.3)$ & $113+286$ \\
\hline & $387 \mathrm{vw}$ & & & & \\
\hline \multicolumn{6}{|l|}{$356 \mathrm{vw}$} \\
\hline \multirow[t]{2}{*}{$313 \mathrm{~m}$} & & $a_{1}$ & $312(0.1)$ & $316(0.1)$ & \\
\hline & $299 \mathrm{~s}$ & $\mathrm{~b}_{2}$ & $278(0.1)$ & $276(0.1)$ & \\
\hline $285 \mathrm{~m}$ & & $\mathrm{a}_{2}$ & $276(0.0)$ & $286(0.0)$ & \\
\hline $264 \mathrm{vw}$ & $261 \mathrm{sh}$ & $\mathrm{b}_{1}$ & $259(11.3)$ & $267(12.0)$ & \\
\hline $240 \mathrm{~m}$ & $238 w$ & $\mathrm{a}_{2}$ & $232(0.0)$ & $236(0.0)$ & \\
\hline $219 \mathrm{~m}$ & $213 w$ & $\mathrm{~b}_{1}$ & $199(0.1)$ & $202(0.1)$ & \\
\hline $166 \mathrm{w}$ & $166 \mathrm{vw}$ & & & & \\
\hline \multirow[t]{5}{*}{$138 \mathrm{~m}$} & $138 \mathrm{w}$ & $\mathrm{a}_{1}$ & $159(0.1)$ & $147(0.1)$ & \\
\hline & & $\mathrm{a}_{2}$ & $115(0.0)$ & $115(0.0)$ & \\
\hline & $121 \mathrm{~m}$ & $\mathrm{~b}_{1}$ & $111(0.6)$ & $113(0.6)$ & \\
\hline & & $\mathrm{b}_{1}$ & $90(0.7)$ & $90(0.2)$ & \\
\hline & & $\mathrm{a}_{2}$ & $83(0.0)$ & $83(0.0)$ & \\
\hline
\end{tabular}

a Infrared intensities (in parentheses) in $\mathrm{km} / \mathrm{mol}$.

b Estimated uncertainties in band positions are within $\pm 3 \mathrm{~cm}^{-1}$. Relative intensities: $\mathrm{vw}=$ very weak, $\mathrm{w}=\mathrm{weak}, \mathrm{m}=\mathrm{medium}, \mathrm{s}=\mathrm{strong}, \mathrm{vs}=\mathrm{very} \mathrm{strong}, \mathrm{sh}=\mathrm{shoulder}$.

c Unscaled DFT frequencies calculated using B3LYP/6-311+G(d,p) as described elsewhere [3].

d Anharmonics B3LYP/6-311 calculation using the $\mathrm{P}_{-} \mathrm{VMWCI}_{2}$ algorithm [21,22].

e A Raman-active dimer vibration was also calculated at $476 \mathrm{~cm}^{-1}$.

f Eigenvector contains $11 \%$ contribution from $3 \times 147 \mathrm{~cm}^{-1}$ overtone.

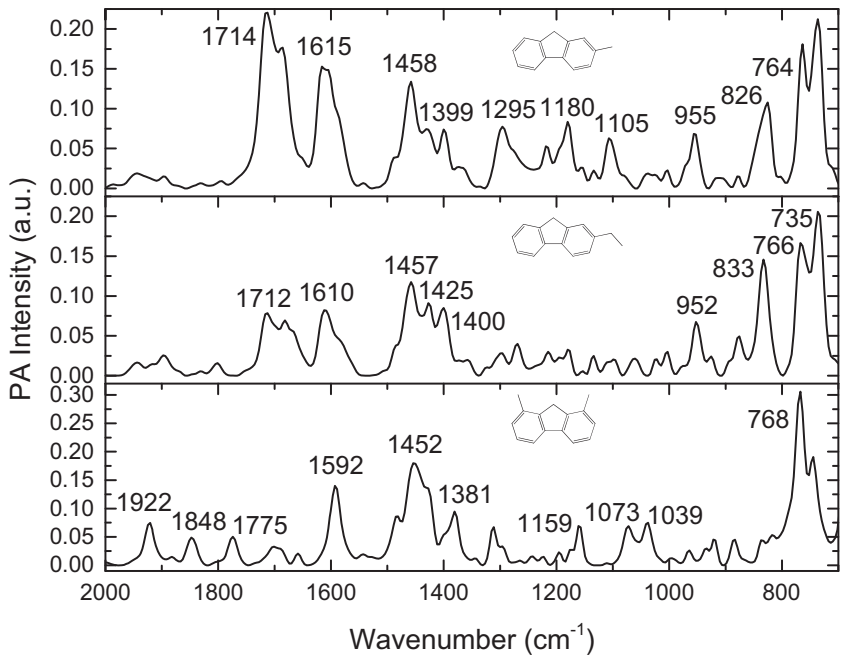

Fig. 8. Fingerprint region PA infrared spectra of 2-methylfluorene (top panel), 2ethylfluorene (middle panel) and 1,8-dimethylfluorene (bottom panel).

higher than the corresponding experimental values. While most of the listed combinations occur above $\sim 1650 \mathrm{~cm}^{-1}$, a few of the weak features at lower wavenumbers undoubtedly have similar origins. It is also interesting to note that vibrations above $1200 \mathrm{~cm}^{-1}$ participate in several combinations for the alkyl derivatives, in contrast with those in Tables 6 and 7. It is reasonable to suggest that the alkyl substituents may play a role in the appearance of these bands.

\section{Summary}

Raman and PA infrared spectra of fluorene, 2,3-benzofluorene, 2-methylfluorene, 2-ethylfluorene and 1,8-dimethylfluorene were acquired and compared with both harmonic (DFT) and anharmonic (variational) calculations in this work. Some of the features observed experimentally were identified for the first time. These include low wavenumber bands for all fluorene derivatives and combination and overtone bands in the low wavenumber and fingerprint regions of the PA infrared spectra. Where available, the measurements in the present work agree with the literature to within applicable experimental errors.

Similarities between the Raman spectra of fluorene and 2,3-benzofluorene were noted in Section 4.2.1. Further examination of the Raman and infrared spectra acquired in this work reveals several regions which contain bands representative of the fluorene family. Characteristic "marker" Raman bands of fluorene (Tables 1 and 6) occur at 417, 542, 741, 842, 1235 and $1612 \mathrm{~cm}^{-1}$; analogous features can be identified for the derivatives (Tables 2-5 and 7-10). The relevant normal modes of the fluorene moiety are illustrated in Table S7 (Supplementary material), which also summarizes the corresponding frequencies in the four derivatives. Similarly, the PA infrared spectra in Figs. 2, 4, 6 and 8 generally exhibit bands near $\sim 470,750,1500-1400$, and $1575 \mathrm{~cm}^{-1}$. Hence observation of bands in these regions could be taken as confirmation of fluorene-like structures within larger aggregates such as asphaltenes or mixtures of polyaromatic hydrocarbons.

Combination and overtone bands appear throughout the farand mid-infrared regions of the PA infrared spectra. These 
Table 6

Raman and PA infrared spectra of fluorene $\left(C_{2 v}\right), 2000-700 \mathrm{~cm}^{-1}$.

\begin{tabular}{|c|c|c|c|c|c|}
\hline \multicolumn{2}{|l|}{ Observed } & \multicolumn{4}{|l|}{ Predicted $^{\mathrm{a}}$} \\
\hline $\operatorname{Raman}^{\mathrm{b}}$ & Infrared $^{\mathrm{b}}$ & Symmetry & Harmonic $^{c}$ & Anharmonic $^{\mathrm{d}}$ & Combination or overtone $^{\mathrm{d}}$ \\
\hline & 1988 vw & & & $1986(0.1)$ & $2 \times 995$ \\
\hline & $1948 \mathrm{~m}$ & & & $1964(0.3)^{e}$ & $2 \times 983$ \\
\hline & 1909 w & & & $1906(0.1)$ & $2 \times 955$ \\
\hline & 1891 w & & & $1901(0.1)$ & $713+1189$ \\
\hline & $1846 \mathrm{vw}$ & & & $1850(0.3)$ & $752+1110$ \\
\hline & $1830 \mathrm{w}$ & & & $1835(0.3)$ & $853+983$ \\
\hline & $1804 \mathrm{~m}$ & & & $1805(0.2)^{\mathrm{f}}$ & $870+936$ \\
\hline & & & & $1760(0.1)$ & $752+1015$ \\
\hline & $1717 \mathrm{w}$ & & & $1739(0.2)$ & $2 \times 870$ \\
\hline & $1690 \mathrm{w}$ & & & $1695(0.1)$ & $752+955$ \\
\hline & $1645 \mathrm{w}$ & & & $1664(0.1)$ & $713+955$ \\
\hline $1625 \mathrm{w}$ & & $\mathrm{b}_{2}$ & $1647(4.0)$ & $1610(2.2)^{g}$ & \\
\hline $1612 \mathrm{~s}$ & $1597 \mathrm{~m}$ & $a_{1}$ & $1646(0.1)$ & $1607(0.0)$ & \\
\hline \multirow[t]{4}{*}{$1577 \mathrm{~m}$} & $1573 \mathrm{~m}$ & $\mathrm{~b}_{2}$ & $1621(0.5)$ & $1580(1.5)$ & \\
\hline & & $a_{1}$ & $1616(1.3)$ & $1601(1.4)$ & \\
\hline & 1525 w & & & & \\
\hline & & $\mathrm{b}_{2}$ & $1508(7.0)$ & $1492(8.1)$ & \\
\hline \multirow[t]{2}{*}{$1508 \mathrm{vw}$} & & $a_{1}$ & $1507(0.0)$ & $1488(0.5)$ & \\
\hline & & $a_{1}$ & $1477(8.9)$ & $1482(0.2)$ & \\
\hline $1479 \mathrm{~m}$ & $1477 \mathrm{~m}$ & $\mathrm{~b}_{2}$ & $1483(19.0)$ & $1467(20.0)$ & \\
\hline $1450 \mathrm{vw}$ & 1447 vs & $a_{1}$ & $1451(12.2)$ & $1445(20.2)$ & \\
\hline \multicolumn{6}{|l|}{$1429 \mathrm{vw}$} \\
\hline \multicolumn{6}{|l|}{$1412 \mathrm{sh}$} \\
\hline $1403 \mathrm{sh}$ & $1401 \mathrm{~s}$ & & & $1402(1.5)$ & $416+983$ \\
\hline \multicolumn{6}{|l|}{$1399 \mathrm{w}$} \\
\hline 1386 vw & $1384 \mathrm{sh}$ & & & & \\
\hline \multicolumn{6}{|l|}{$1369 \mathrm{vw}$} \\
\hline $1351 \mathrm{sh}$ & & $a_{1}$ & $1374(0.3)$ & $1370(0.0)$ & \\
\hline $1344 \mathrm{w}$ & $1341 \mathrm{~m}$ & $\mathrm{~b}_{2}$ & $1345(7.1)$ & $1349(8.4)$ & \\
\hline $1325 \mathrm{w}$ & & $\mathrm{b}_{2}$ & $1329(2.5)$ & $1328(0.8)$ & \\
\hline $1300 \mathrm{w}$ & $1310 \mathrm{~m}$ & $a_{1}$ & $1320(0.4)$ & $1314(4.1)$ & \\
\hline $1292 \mathrm{~m}$ & $1300 \mathrm{sh}$ & & & & \\
\hline $1268 \mathrm{vw}$ & & $a_{1}$ & $1252(3.0)$ & $1238(4.0)$ & \\
\hline 1235 vs & $1231 \mathrm{w}$ & $b_{2}$ & $1221(3.9)$ & $1208(0.6)$ & \\
\hline $1221 \mathrm{vw}$ & $1219 \mathrm{vw}$ & & & & \\
\hline $1210 \mathrm{vw}$ & & $a_{1}$ & $1207(2.9)$ & $1201(0.9)$ & \\
\hline 1193 w & $1188 \mathrm{~m}$ & $\mathrm{~b}_{2}$ & $1192(3.0)$ & $1194(3.1)$ & \\
\hline $1188 \mathrm{w}$ & & $a_{1}$ & $1180(0.1)$ & $1189(0.1)$ & \\
\hline $1169 \mathrm{vw}$ & & $b_{2}$ & $1176(0.2)$ & $1181(0.1)$ & \\
\hline $1153 \mathrm{~m}$ & $1155 \mathrm{~m}$ & $\mathrm{a}_{2}$ & $1162(0.0)$ & $1156(0.2)$ & \\
\hline \multicolumn{6}{|l|}{$1146 \mathrm{w}$} \\
\hline 1127 vw & $1122 \mathrm{sh}$ & & & & \\
\hline \multicolumn{6}{|l|}{$1115 \mathrm{vw}$} \\
\hline $1107 \mathrm{vw}$ & $1108 \mathrm{~m}$ & $\mathrm{~b}_{2}$ & $1130(0.1)$ & $1119(0.1)$ & \\
\hline \multirow[t]{2}{*}{$1092 \mathrm{vw}$} & $1091 \mathrm{~m}$ & $\mathrm{a}_{1}$ & $1117(3.3)$ & $1110(3.0)$ & \\
\hline & $1061 \mathrm{vw}$ & $\mathrm{b}_{2}$ & $1051(5.8)$ & $1047(2.4)$ & \\
\hline 1020 vs & $1020 \mathrm{~m}$ & $a_{1}$ & $1045(0.9)$ & $1029(0.7)$ & \\
\hline \multicolumn{6}{|l|}{$1002 \mathrm{vw}$} \\
\hline \multirow[t]{2}{*}{$993 \mathrm{vw}$} & $997 \mathrm{~m}$ & $\mathrm{~b}_{2}$ & $1023(4.6)$ & $1015(5.3)$ & \\
\hline & & $\mathrm{b}_{1}$ & $994(0.1)$ & $995(0.2)$ & \\
\hline $973 \mathrm{vw}$ & $979 \mathrm{sh}$ & $a_{2}$ & $993(0.0)$ & $992(0.0)$ & \\
\hline $955 \mathrm{vw}$ & $953 \mathrm{~m}$ & $\mathrm{~b}_{1}$ & $976(4.2)$ & $983(4.7)$ & \\
\hline & & $a_{2}$ & $956(0.0)$ & $955(0.3)$ & \\
\hline $917 \mathrm{vw}$ & $910 \mathrm{vw}$ & $\mathrm{b}_{1}$ & $933(0.1)$ & $936(0.1)$ & \\
\hline & $881 \mathrm{vw}$ & $a_{2}$ & $880(0.0)$ & $880(0.1)$ & \\
\hline $864 \mathrm{vw}$ & $859 \mathrm{~m}$ & $b_{1}$ & $871(0.6)$ & $870(1.2)$ & \\
\hline $852 w$ & & & & & \\
\hline $842 \mathrm{~m}$ & & $a_{1}$ & $853(0.1)$ & $853(0.2)$ & \\
\hline & 820 vw & $\mathrm{b}_{2}$ & $813(0.4)$ & $807(0.6)$ & \\
\hline $786 \mathrm{w}$ & 792 vw & $\mathrm{a}_{2}$ & $792(0.0)$ & $799(0.1)$ & \\
\hline $781 \mathrm{w}$ & $775 \mathrm{sh}$ & & & & \\
\hline 741 vs & & $a_{1}$ & $755(0.1)$ & $743(0.0)$ & \\
\hline & $741 \mathrm{vs}$ & $\mathrm{b}_{1}$ & $754(134.8)$ & $752(132.1)$ & \\
\hline & & $a_{2}$ & $738(0.0)$ & $736(0.0)$ & \\
\hline & & $\mathrm{b}_{1}$ & $710(5.4)$ & $713(2.9)$ & \\
\hline
\end{tabular}

a Infrared intensities (in parentheses) in $\mathrm{km} / \mathrm{mol}$.

b Estimated uncertainties in band positions are within $\pm 3 \mathrm{~cm}^{-1}$. Relative intensities: $\mathrm{vw}=$ very weak, $\mathrm{w}=\mathrm{weak}, \mathrm{m}=\mathrm{medium}, \mathrm{s}=\mathrm{strong}, \mathrm{vs}=\mathrm{very}$ strong, sh $=\mathrm{shoulder}$.

c Unscaled DFT frequencies calculated using B3LYP/6-311+G(d,p) as described elsewhere [3].

d Anharmonics B3LYP/6-311 calculation using the P_VMWCI 2 algorithm [21,22].

e Eigenvector contains $6 \%$ contribution from $3 \times 983 \mathrm{~cm}^{-1}$ overtone.

f Eigenvector contains 5\% contribution from $2 \times 870 \mathrm{~cm}^{-1}$ overtone.

g Eigenvector contains $7 \%$ contribution from $807+743 \mathrm{~cm}^{-1}$ combination. 
Table 7

Raman and PA infrared spectra of 2,3-benzofluorene $\left(C_{s}\right), 2000-700 \mathrm{~cm}^{-1}$.

\begin{tabular}{|c|c|c|c|c|c|}
\hline \multicolumn{2}{|l|}{ Observed } & \multicolumn{4}{|l|}{ Predicted $^{\mathrm{a}}$} \\
\hline $\operatorname{Raman}^{\mathrm{b}}$ & Infrared $^{\mathrm{b}}$ & Symmetry & Harmonic $^{\mathrm{c}}$ & Anharmonic $^{\mathrm{d}}$ & Combination or overtone $^{\mathrm{d}}$ \\
\hline & $1949 \mathrm{w}$ & & & & \\
\hline & 1924 w & & & $1891(0.3)^{e}$ & $892+1027$ \\
\hline & 1905 w & & & $1898(0.1)$ & $2 \times 950$ \\
\hline & $1880 \mathrm{vw}$ & & & & \\
\hline & $1840 \mathrm{vw}$ & & & $1825(0.3)$ & $892+950$ \\
\hline & $1815 \mathrm{w}$ & & & $1831(0.7)$ & $804+1027$ \\
\hline & $1792 \mathrm{sh}$ & & & $1783(0.1)$ & $760+1027$ \\
\hline & $1761 \mathrm{w}$ & & & & \\
\hline & $1719 \mathrm{w}$ & & & $1738(0.1)$ & $760+950$ \\
\hline & $1700 \mathrm{w}$ & & & $1714(0.1), 1696(0.1)$ & $804+914,804+892$ \\
\hline \multirow[t]{2}{*}{$1640 \mathrm{~m}$} & 1635 w & $a^{\prime}$ & $1673(2.7)$ & $1642(1.0)^{\mathrm{f}}$ & \\
\hline & & $a^{\prime}$ & $1649(1.5)$ & $1616(2.2)$ & \\
\hline \multirow[t]{2}{*}{$1606 \mathrm{~m}$} & $1607 \mathrm{~m}$ & $a^{\prime}$ & $1645(1.0)$ & $1614(0.7)$ & \\
\hline & & $a^{\prime}$ & $1620(1.5)$ & $1608(0.4)$ & \\
\hline $1577 \mathrm{w}$ & & $a^{\prime}$ & $1613(1.0)$ & $1577(0.3)$ & \\
\hline $1499 \mathrm{~m}$ & $1500 \mathrm{~m}$ & $a^{\prime}$ & $1536(12.1)$ & $1517(11.1)$ & \\
\hline \multirow[t]{4}{*}{$1473 \mathrm{~m}$} & $1470 \mathrm{~m}$ & $a^{\prime}$ & $1503(3.9)$ & $1482(0.9)$ & \\
\hline & & $a^{\prime}$ & $1500(6.8)$ & $1489(0.2)$ & \\
\hline & & $a^{\prime}$ & $1479(2.9)$ & $1477(0.1)$ & \\
\hline & & $a^{\prime}$ & $1467(14.0)$ & $1466(5.1)$ & \\
\hline $1436 s$ & $1436 \mathrm{~m}$ & $a^{\prime}$ & $1455(14.3)$ & $1444(18.8)$ & \\
\hline $1409 \mathrm{~m}$ & $1407 \mathrm{~m}$ & $a^{\prime}$ & $1425(0.2)$ & $1410(1.9)$ & \\
\hline 1395 w & & $a^{\prime}$ & $1390(0.8)$ & $1386(0.2)$ & \\
\hline \multicolumn{6}{|l|}{$1384 \mathrm{w}$} \\
\hline $1368 \mathrm{~s}$ & 1363 vw & $a^{\prime}$ & $1368(2.6)$ & $1361(1.0)$ & \\
\hline \multirow[t]{2}{*}{1342 vw } & $1340 \mathrm{~m}$ & $a^{\prime}$ & $1351(8.6)$ & $1334(4.9)$ & \\
\hline & $1315 \mathrm{~m}$ & $a^{\prime}$ & $1326(0.1)$ & $1320(0.0)$ & \\
\hline \multicolumn{6}{|l|}{1302 vw } \\
\hline & $1265 \mathrm{~m}$ & $a^{\prime}$ & $1283(5.1)$ & $1289(5.6)$ & \\
\hline & & $a^{\prime}$ & $1261(0.9)$ & $1256(0.1)$ & \\
\hline $1238 \mathrm{~m}$ & $1236 \mathrm{w}$ & $a^{\prime}$ & $1250(1.7)$ & $1243(1.5)$ & \\
\hline $1226 \mathrm{w}$ & & $a^{\prime}$ & $1224(0.6)$ & $1225(0.1)^{g}$ & \\
\hline $1204 \mathrm{vw}$ & & $a^{\prime}$ & $1213(6.6)$ & $1206(0.2)$ & \\
\hline \multirow[t]{2}{*}{$1190 \mathrm{~m}$} & 1194 w & $a^{\prime}$ & $1197(1.6)$ & $1187(2.6)$ & \\
\hline & $1179 \mathrm{sh}$ & $a^{\prime}$ & $1179(0.3)$ & $1176(0.5)$ & \\
\hline \multirow[t]{2}{*}{$1154 \mathrm{w}$} & $1149 \mathrm{~m}$ & $a^{\prime}$ & $1174(3.6)$ & $1170(3.5)$ & \\
\hline & & $a^{\prime}$ & $1169(2.7)$ & $1160(0.1)$ & \\
\hline $1144 \mathrm{w}$ & & $a^{\prime \prime}$ & $1165(0.1)$ & $1142(0.0)$ & \\
\hline 1117 vw & $1116 \mathrm{w}$ & $a^{\prime}$ & $1136(2.6)$ & $1125(1.3)$ & \\
\hline \multirow[t]{2}{*}{1099 vw } & 1094 w & $a^{\prime}$ & $1116(0.9)$ & $1110(0.9)$ & \\
\hline & $1058 \mathrm{vw}$ & $a^{\prime}$ & $1046(5.5)$ & $1044(0.1)$ & \\
\hline \multirow[t]{4}{*}{$1021 \mathrm{~s}$} & 1017 m & $a^{\prime}$ & $1041(4.2)$ & $1027(3.8)$ & \\
\hline & & $a^{\prime}$ & $998(0.9)$ & $997(0.2)$ & \\
\hline & & $a^{\prime \prime}$ & $994(0.1)$ & $990(0.1)$ & \\
\hline & & $a^{\prime \prime}$ & $993(0.1)$ & $990(0.1)$ & \\
\hline \multirow[t]{2}{*}{$981 \mathrm{w}$} & 978 w & $a^{\prime \prime}$ & $976(8.2)$ & $984(1.5)$ & \\
\hline & & $a^{\prime \prime}$ & $969(0.5)$ & $974(0.9)$ & \\
\hline $951 \mathrm{vw}$ & $951 \mathrm{~m}$ & $a^{\prime \prime}$ & $946(0.8)$ & $950(0.2)$ & \\
\hline $931 \mathrm{vw}$ & 928 w & $a^{\prime}$ & $909(0.4)$ & $914(0.3)$ & \\
\hline 896 vw & & $a^{\prime \prime}$ & $903(2.4)$ & $914(0.5)$ & \\
\hline \multirow[t]{3}{*}{$876 \mathrm{vw}$} & $874 \mathrm{~s}$ & $a^{\prime \prime}$ & $888(27.9)$ & $892(27.7)$ & \\
\hline & & $a^{\prime \prime}$ & $876(0.3)$ & $870(0.1)$ & \\
\hline & & $a^{\prime \prime}$ & $857(0.1)$ & $852(0.1)$ & \\
\hline $833 \mathrm{~s}$ & & $a^{\prime}$ & $842(0.1)$ & $842(0.3)$ & \\
\hline 814 vw & $820 \mathrm{~m}$ & $a^{\prime \prime}$ & $782(49.6)$ & $804(12.4)$ & \\
\hline 796 vw & & $a^{\prime}$ & $803(0.1)$ & $797(0.1)$ & \\
\hline \multirow{2}{*}{$773 w$} & & $a^{\prime \prime}$ & $772(14.2)$ & $776(3.8)$ & \\
\hline & $763 \mathrm{~s}$ & $a^{\prime}$ & $766(0.1)$ & $759(0.1)$ & \\
\hline 752 vs & & $a^{\prime \prime}$ & $755(12.9)$ & $760(14.2)$ & \\
\hline $734 \mathrm{w}$ & $728 \mathrm{~s}$ & $a^{\prime \prime}$ & $736(44.0)$ & $741(44.8)$ & \\
\hline $700 w$ & $700 \mathrm{sh}$ & $a^{\prime}$ & $713(2.1)$ & $719(1.4)$ & \\
\hline
\end{tabular}

${ }^{\text {a }}$ Infrared intensities (in parentheses) in $\mathrm{km} / \mathrm{mol}$.

b Estimated uncertainties in band positions are within $\pm 3 \mathrm{~cm}^{-1}$. Relative intensities: $\mathrm{vw}=$ very weak, $\mathrm{w}=\mathrm{weak}, \mathrm{m}=\mathrm{medium}, \mathrm{s}=\mathrm{strong}, \mathrm{vs}=\mathrm{very} \mathrm{strong}, \mathrm{sh}=\mathrm{shoulder}$.

c Unscaled DFT frequencies calculated using B3LYP/6-311+G(d,p) as described elsewhere [3].

d Anharmonics B3LYP/6-311 calculation using the $\mathrm{P}_{-} \mathrm{VMWCI}_{2}$ algorithm [21,22].

e Eigenvector contains 5\% contribution from $852+842 \mathrm{~cm}^{-1}$ combination.

${ }^{f}$ Eigenvector contains $10 \%$ contribution from $2 \times 804 \mathrm{~cm}^{-1}$ overtone and $5 \%$ contribution from $2 \times 792 \mathrm{~cm}^{-1}$ overtone.

g A Raman-active dimer vibration was also calculated at $1231 \mathrm{~cm}^{-1}$. 
Table 8

Raman and PA infrared spectra of 2-methylfluorene $\left(C_{1}\right), 2000-700 \mathrm{~cm}^{-1}$

\begin{tabular}{|c|c|c|c|c|}
\hline \multicolumn{2}{|l|}{ Observed } & \multicolumn{3}{|l|}{ Predicted $^{\mathrm{a}}$} \\
\hline $\operatorname{Raman}^{\mathrm{b}}$ & $\overline{\text { Infrared }^{\mathrm{b}}}$ & Harmonic $^{c}$ & Anharmonic $^{\mathrm{d}}$ & Combination or overtone $^{\mathrm{d}}$ \\
\hline & 1945 w & & $1964(0.8)$ & $756+1216$ \\
\hline & $1896 \mathrm{w}$ & & & \\
\hline & $1831 \mathrm{vw}$ & & $1849(0.1)^{\mathrm{e}}$ & $756+1109$ \\
\hline & $1795 \mathrm{vw}$ & & $1802(0.1)$ & $591+1216$ \\
\hline \multirow[t]{3}{*}{$1713 \mathrm{~m}$} & 1714 vs & $1654(3.9)$ & $1610(4.2)$ & \\
\hline & $1686 \mathrm{sh}$ & $1646(6.0)$ & $1600(3.5)$ & \\
\hline & $1652 \mathrm{vw}$ & & $1658(1.1)^{\mathrm{f}}$ & $2 \times 830$ \\
\hline $1619 \mathrm{sh}$ & $1615 \mathrm{~s}$ & $1620(0.4)$ & $1584(3.2)$ & \\
\hline $1611 \mathrm{~m}$ & $1605 \mathrm{sh}$ & $1614(2.2)$ & $1572(0.7)$ & \\
\hline \multicolumn{5}{|l|}{$1587 \mathrm{sh}$} \\
\hline \multicolumn{5}{|l|}{1577 vw } \\
\hline \multirow[t]{3}{*}{$1550 \mathrm{~m}$} & $1543 \mathrm{vw}$ & & & \\
\hline & & $1517(7.2)$ & $1504(7.0)$ & \\
\hline & & $1504(8.0)$ & $1489(10.8)^{g}$ & \\
\hline \multirow{2}{*}{$1487 \mathrm{w}$} & $1487 \mathrm{sh}$ & $1491(21.2)$ & $1480(15.2)$ & \\
\hline & & $1489(7.1)$ & $1473(15.0)$ & \\
\hline $1462 \mathrm{w}$ & $1458 \mathrm{~s}$ & $1484(14.2)$ & $1469(12.8)$ & \\
\hline $1430 \mathrm{w}$ & $1429 \mathrm{sh}$ & $1452(4.0)$ & $1450(2.0)$ & \\
\hline \multirow[t]{2}{*}{1403 vw } & & $1449(2.5)$ & $1436(5.6)$ & \\
\hline & & & $1416(0.2)$ & $434+987$ \\
\hline 1395 vw & $1399 \mathrm{~m}$ & $1413(0.1)$ & $1404(0.0)$ & \\
\hline $1378 \mathrm{vw}$ & $1375 \mathrm{sh}$ & & $1401(0.3)$ & $250+1153$ \\
\hline $1364 \mathrm{vw}$ & $1366 \mathrm{sh}$ & $1371(0.4)$ & $1360(0.6)$ & \\
\hline \multicolumn{5}{|l|}{$1345 \mathrm{sh}$} \\
\hline 1337 w & $1336 \mathrm{vw}$ & $1336(12.7)$ & $1328(3.0)$ & \\
\hline 1306 w & & $1327(1.1)$ & $1315(4.6)$ & \\
\hline $1291 \mathrm{~m}$ & $1295 \mathrm{~m}$ & $1316(0.9)$ & $1314(0.5)$ & \\
\hline \multirow[t]{2}{*}{$1247 \mathrm{~m}$} & $1247 \mathrm{vw}$ & $1267(2.3)$ & $1246(2.0)$ & \\
\hline & & $1236(1.9)$ & $1235(1.1)$ & \\
\hline $1220 \mathrm{~m}$ & $1218 \mathrm{~m}$ & $1221(3.0)$ & $1216(1.8)$ & \\
\hline \multicolumn{5}{|l|}{$1208 \mathrm{w}$} \\
\hline 1197 vw & $1195 \mathrm{sh}$ & $1198(3.4)$ & $1195(3.0)$ & \\
\hline \multirow[t]{2}{*}{$1182 \mathrm{w}$} & $1180 \mathrm{~m}$ & $1179(0.3)$ & $1183(0.1)$ & \\
\hline & & $1162(0.1)$ & $1158(0.0)$ & \\
\hline \multirow[t]{2}{*}{$1154 \mathrm{w}$} & $1156 \mathrm{vw}$ & $1157(2.7)$ & $1153(1.6)$ & \\
\hline & $1105 \mathrm{~m}$ & $1120(1.9)$ & $1109(1.8)$ & \\
\hline \multirow[t]{2}{*}{$1097 \mathrm{w}$} & & $1059(11.4)$ & $1081(5.0)$ & \\
\hline & $1039 \mathrm{w}$ & $1048(4.8)$ & $1043(6.6)$ & \\
\hline $1025 \mathrm{~m}$ & $1026 \mathrm{sh}$ & $1024(3.1)$ & $1030(0.6)$ & \\
\hline \multirow[t]{2}{*}{$1004 \mathrm{~m}$} & $1003 \mathrm{w}$ & $1015(0.3)$ & $1019(0.1)$ & \\
\hline & & $992(0.1)$ & $987(0.0)$ & \\
\hline 974 vw & $972 \mathrm{sh}$ & $974(3.6)$ & $987(2.2)$ & \\
\hline \multirow[t]{2}{*}{$960 \mathrm{w}$} & $955 \mathrm{~m}$ & $961(0.3)$ & $964(0.1)$ & \\
\hline & & $941(0.3)$ & $936(0.2)$ & \\
\hline \multirow[t]{2}{*}{$916 \mathrm{vw}$} & $916 \mathrm{w}$ & $927(0.8)$ & $919(0.8)$ & \\
\hline & $878 \mathrm{w}$ & $889(1.9)$ & $910(1.1)$ & \\
\hline \multirow[t]{2}{*}{853 vw } & $820 \mathrm{~m}$ & $874(0.1)$ & $877(0.0)$ & \\
\hline & & $837(1.2)$ & $831(0.4)$ & \\
\hline $828 \mathrm{~m}$ & $826 \mathrm{~s}$ & $833(18.2)$ & $830(15.0)$ & \\
\hline 804 vw & 804 vw & & & \\
\hline & 764 vs & $776(45.3)$ & $786(44.5)$ & \\
\hline 757 vs & & $771(1.3)$ & $763(0.2)$ & \\
\hline $733 \mathrm{~m}$ & 736 vs & $743(39.6)$ & $756(39.0)$ & \\
\hline $716 \mathrm{w}$ & & $722(1.1)$ & $723(0.9)$ & \\
\hline $710 \mathrm{vw}$ & & $711(0.1)$ & $721(0.1)$ & \\
\hline
\end{tabular}

a Infrared intensities (in parentheses) in $\mathrm{km} / \mathrm{mol}$.

b Estimated uncertainties in band positions are within $\pm 3 \mathrm{~cm}^{-1}$. Relative intensities: $v \mathrm{w}=$ very weak, $\mathrm{w}=\mathrm{weak}, \mathrm{m}=\mathrm{medium}, \mathrm{s}=\mathrm{strong}, \mathrm{vs}=\mathrm{very}$ strong, sh $=\mathrm{shoulder}$.

c Unscaled DFT frequencies calculated using B3LYP/6-311+G(d,p) as described elsewhere [3].

d Anharmonics B3LYP/6-311 calculation using the $\mathrm{P}_{-} \mathrm{VMWCI}_{2}$ algorithm $[21,22]$.

e Eigenvector contains $5 \%$ contribution from $1019+830 \mathrm{~cm}^{-1}$ combination.

f Eigenvector contains $8 \%$ contribution from $2 \times 831 \mathrm{~cm}^{-1}$ overtone and $5 \%$ contribution from $831+830 \mathrm{~cm}^{-1} \mathrm{combination}^{-1}$

g Eigenvector contains $7 \%$ contribution from $763+756 \mathrm{~cm}^{-1}$ combination.

features are most noticeable between about 2700 and $1640 \mathrm{~cm}^{-1}$, since no fundamental vibrations occur in this interval for the compounds studied in this work. The occurrence of these features in PA spectra of condensed-ring hydrocarbons appears to be a general phenomenon. This contention is supported by separate PA measurements made using a quantum cascade laser [36].

The computed spectra and the measured spectra agree with one another with respect to the values of the wavenumbers. Relative peak intensities show poorer agreement due to several factors. These include partial saturation in the PA spectra, which tends to limit the intensities of strong bands while enhancing relative intensities of weaker features. Saturation also tends to increase bandwidths. Moreover, the experimental Raman and infrared spectra are affected by solid-state interactions which are not explicitly taken into consideration in the DFT calculations. Our choice of basis set for these calculations could be another relevant factor. As a 
Table 9

Raman and PA infrared spectra of 2-ethylfluorene $\left(C_{1}\right), 2000-700 \mathrm{~cm}^{-1}$.

\begin{tabular}{|c|c|c|c|c|}
\hline \multicolumn{2}{|l|}{ Observed } & \multicolumn{3}{|l|}{ Predicted $^{\mathrm{a}}$} \\
\hline Raman $^{\mathrm{b}}$ & Infrared $^{\mathrm{b}}$ & Harmonic $^{c}$ & Anharmonic $^{\mathrm{d}}$ & Combination or overtone $^{\mathrm{d}}$ \\
\hline & 1943 vw & & $1967(0.1)$ & $891+1077$ \\
\hline & $1917 \mathrm{sh}$ & & $1900(0.1)$ & $744+1160$ \\
\hline & $1895 \mathrm{w}$ & & $1894(0.1)$ & $2 \times 949$ \\
\hline & $1830 \mathrm{vw}$ & & $1831(0.8)$ & $744+1077$ \\
\hline & 1799 w & & & \\
\hline \multirow[t]{2}{*}{$1715 \mathrm{vw}$} & $1712 \mathrm{~m}$ & & $1704(0.9)$ & $2 \times 853$ \\
\hline & $1683 \mathrm{w}$ & & & \\
\hline 1612 vs & $1610 \mathrm{~m}$ & $1652(1.9)$ & $1626(2.5)$ & \\
\hline \multirow[t]{6}{*}{$1579 \mathrm{w}$} & & $1646(6.0)$ & $1614(3.6)$ & \\
\hline & & $1619(0.6)$ & $1607(0.3)$ & \\
\hline & $1540 \mathrm{sh}$ & $1612(1.0)$ & $1579(0.9)$ & \\
\hline & & $1517(7.5)$ & $1510(0.2)^{\mathrm{e}}$ & \\
\hline & & $1508(3.2)$ & $1506(0.3)$ & \\
\hline & & $1498(13.1)$ & $1495(0.5)$ & \\
\hline $1489 \mathrm{w}$ & & $1497(10.0)$ & $1480(1.4)$ & \\
\hline 1468 vw & & $1491(7.4)$ & $1489(6.4)$ & \\
\hline $1459 \mathrm{vw}$ & $1457 \mathrm{~m}$ & $1486(9.9)$ & $1477(14.0)$ & \\
\hline 1443 vw & & $1457(7.8)$ & $1440(10.9)$ & \\
\hline 1426 w & $1425 \mathrm{~m}$ & $1451(9.8)$ & $1428(3.5)$ & \\
\hline \multirow[t]{4}{*}{$1402 \mathrm{w}$} & $1400 \mathrm{~m}$ & $1409(3.4)$ & $1400(3.2)$ & \\
\hline & & $1374(0.1)$ & $1368(0.1)$ & \\
\hline & 1359 vw & $1352(2.8)$ & $1349(2.8)$ & \\
\hline & & $1343(15.3)$ & $1339(2.3)$ & \\
\hline $1343 \mathrm{~m}$ & & $1327(0.5)$ & $1320(1.1)$ & \\
\hline $1305 \mathrm{~m}$ & & $1321(1.2)$ & $1314(1.7)$ & \\
\hline \multirow[t]{2}{*}{$1297 \mathrm{sh}$} & $1299 \mathrm{w}$ & & & \\
\hline & & $1271(1.0)$ & $1270(0.4)$ & \\
\hline $1271 \mathrm{w}$ & $1269 \mathrm{w}$ & $1264(1.6)$ & $1265(0.6)$ & \\
\hline $1242 \mathrm{~m}$ & & $1234(2.2)$ & $1249(0.3)$ & \\
\hline $1217 \mathrm{vw}$ & $1215 \mathrm{w}$ & $1220(3.0)$ & $1214(2.0)$ & \\
\hline 1196 vw & $1194 \mathrm{vw}$ & $1198(3.7)$ & $1197(3.0)$ & \\
\hline \multirow[t]{2}{*}{$1178 \mathrm{vw}$} & $1179 \mathrm{w}$ & $1179(0.2)$ & $1194(0.1)$ & \\
\hline & & $1161(0.1)$ & $1152(0.0)$ & \\
\hline $1154 \mathrm{w}$ & $1152 \mathrm{vw}$ & $1158(3.6)$ & $1160(4.0)$ & \\
\hline $1137 \mathrm{vw}$ & $1137 \mathrm{w}$ & $1144(0.4)$ & $1135(0.1)$ & \\
\hline \multirow[t]{2}{*}{$1124 \mathrm{vw}$} & & $1121(1.9)$ & $1120(1.7)$ & \\
\hline & $1109 \mathrm{vw}$ & & & \\
\hline $1098 \mathrm{w}$ & $1097 \mathrm{vw}$ & $1080(10.3)$ & $1077(9.0)$ & \\
\hline \multirow[t]{2}{*}{$1064 \mathrm{w}$} & $1063 \mathrm{w}$ & $1075(3.3)$ & $1082(3.3)$ & \\
\hline & & $1048(3.8)$ & $1040(1.2)$ & \\
\hline $1027 \mathrm{~m}$ & $1025 \mathrm{vw}$ & $1024(4.3)$ & $1022(4.3)$ & \\
\hline \multirow[t]{2}{*}{$1006 \mathrm{w}$} & 1003 w & & & \\
\hline & & $992(0.1)$ & $996(0.1)$ & \\
\hline \multirow[t]{5}{*}{$978 \mathrm{vw}$} & & $982(0.6)$ & $969(0.2)$ & \\
\hline & $976 \mathrm{sh}$ & $974(3.5)$ & $984(3.0)$ & \\
\hline & $952 \mathrm{~m}$ & $963(0.6)$ & $949(0.2)$ & \\
\hline & $926 \mathrm{vw}$ & $942(0.5)$ & $940(0.2)$ & \\
\hline & & $906(2.1)$ & $903(2.2)$ & \\
\hline \multirow[t]{2}{*}{$896 \mathrm{vw}$} & $892 \mathrm{sh}$ & $893(3.5)$ & $891(2.0)$ & \\
\hline & $876 \mathrm{~m}$ & $874(0.1)$ & $872(0.1)$ & \\
\hline \multicolumn{5}{|l|}{$860 \mathrm{vw}$} \\
\hline \multirow{4}{*}{$824 \mathrm{~m}$} & $833 \mathrm{~s}$ & $842(18.3)$ & $853(17.0)$ & \\
\hline & & $836(0.4)$ & $832(0.1)$ & \\
\hline & & $792(0.7)$ & $790(0.3)$ & \\
\hline & & $781(24.1)$ & $783(23.2)$ & \\
\hline $755 \mathrm{~s}$ & $766 \mathrm{~s}$ & $769(1.5)$ & $762(0.2)$ & \\
\hline \multirow[t]{2}{*}{$730 w$} & $735 \mathrm{~s}$ & $747(58.4)$ & $744(55.5)$ & \\
\hline & & $721(0.5)$ & $719(0.2)$ & \\
\hline $708 \mathrm{vw}$ & & $713(0.9)$ & $719(0.9)$ & \\
\hline
\end{tabular}

a Infrared intensities (in parentheses) in $\mathrm{km} / \mathrm{mol}$.

b Estimated uncertainties in band positions are within $\pm 3 \mathrm{~cm}^{-1}$. Relative intensities: vw $=$ very weak, $\mathrm{w}=\mathrm{weak}, \mathrm{m}=\mathrm{medium}, \mathrm{s}=\mathrm{strong}, \mathrm{vs}=\mathrm{very}$ strong, $\mathrm{sh}=\mathrm{shoulder}$.

c Unscaled DFT frequencies calculated using B3LYP/6-311+G(d,p) as described elsewhere [3].

d Anharmonics B3LYP/6-311 calculation using the $\mathrm{P}_{-} \mathrm{VMWCI}_{2}$ algorithm [21,22].

e Eigenvector contains $5 \%$ contribution from $783+719 \mathrm{~cm}^{-1}$ combination.

consequence, predicted and observed relative intensities show only qualitative agreement in some cases.

Band frequencies in the observed spectra correspond closely to computed fundamental, combination, and overtone bands attesting to the anharmonic (mechanical and electrical) character of the vibrations. Many peaks appear in both the experimental Raman and infrared spectra, including numerous examples where the calculations, based on the behavior of individual molecules, predict activity in only one type of spectrum. This apparent disagreement, which also arises in the acene family [1,2], was resolved by performing calculations with slightly distorted molecules [37]. Small symmetry breaking distortions may arise in crystal lattices and permit bands to be both IR and Raman active. 
Table 10

Raman and PA infrared spectra of 1,8-dimethylfluorene $\left(C_{2 v}\right), 2000-700 \mathrm{~cm}^{-1}$.

\begin{tabular}{|c|c|c|c|c|c|}
\hline \multicolumn{2}{|l|}{ Observed } & \multicolumn{4}{|l|}{ Predicted $^{\mathrm{a}}$} \\
\hline $\operatorname{Raman}^{\mathrm{b}}$ & Infrared $^{\mathrm{b}}$ & Symmetry & Harmonic $^{c}$ & Anharmonic ${ }^{\mathrm{d}}$ & Combination $^{\mathrm{d}}$ \\
\hline & $1922 \mathrm{~m}$ & & & $1917(0.5)$ & $460+1465$ \\
\hline & 1883 vw & & & & \\
\hline & $1848 \mathrm{w}$ & & & & \\
\hline & $1775 \mathrm{w}$ & & & $1772(0.8)$ & $780+993$ \\
\hline & $1700 \mathrm{w}$ & & & $1708(0.3)$ & $543+1167$ \\
\hline & $1692 \mathrm{sh}$ & & & & \\
\hline & 1659 vw & & & & \\
\hline \multirow[t]{9}{*}{1602 vs } & & $\mathrm{b}_{2}$ & $1636(1.3)$ & $1608(0.3)$ & \\
\hline & $1592 \mathrm{~m}$ & $a_{1}$ & $1636(4.9)$ & $1599(1.9)^{\mathrm{e}}$ & \\
\hline & & $b_{2}$ & $1629(14.6)$ & $1599(5.0)$ & \\
\hline & & $a_{1}$ & $1626(12.7)$ & $1590(8.2)^{\mathrm{f}}$ & \\
\hline & 1544 vw & & & $1554(0.9)$ & $2 \times 780$ \\
\hline & & $\mathrm{b}_{2}$ & $1517(0.3)$ & $1510(0.1)$ & \\
\hline & & $a_{1}$ & $1515(4.5)$ & $1503(0.1)$ & \\
\hline & & $b_{2}$ & $1500(34.4)$ & $1490(15.4)$ & \\
\hline & & $a_{1}$ & $1497(4.0)$ & $1485(0.2)$ & \\
\hline \multirow[t]{3}{*}{$1484 \mathrm{w}$} & $1483 \mathrm{sh}$ & $b_{1}$ & $1488(18.3)$ & $1465(20.7)$ & \\
\hline & & $a_{2}$ & $1487(0.0)$ & $1481(0.0)$ & \\
\hline & $1452 \mathrm{~s}$ & $b_{2}$ & $1457(4.2)$ & $1443(2.5)$ & \\
\hline \multirow[t]{3}{*}{$1418 \mathrm{w}$} & $1428 \mathrm{sh}$ & $a_{1}$ & $1454(0.1)$ & $1425(0.9)$ & \\
\hline & & $a_{1}$ & $1438(10.3)$ & $1415(7.0)$ & \\
\hline & $1400 \mathrm{sh}$ & $a_{1}$ & $1416(3.4)$ & $1407(0.6)$ & \\
\hline $1380 \mathrm{w}$ & $1381 \mathrm{~m}$ & $b_{2}$ & $1415(0.1)$ & $1412(0.0)$ & \\
\hline \multirow[t]{3}{*}{$1344 \mathrm{~m}$} & 1344 vw & $\mathrm{a}_{1}$ & $1372(0.3)$ & $1360(0.2)$ & \\
\hline & & $b_{2}$ & $1343(4.2)$ & $1337(1.0)$ & \\
\hline & $1312 \mathrm{~m}$ & $a_{1}$ & $1315(2.4)$ & $1319(2.0)$ & \\
\hline $1292 \mathrm{~s}$ & $1296 \mathrm{sh}$ & $b_{2}$ & $1293(0.7)$ & $1301(0.2)$ & \\
\hline $1260 \mathrm{sh}$ & $1265 \mathrm{vw}$ & $a_{1}$ & $1265(2.7)$ & $1253(3.1)$ & \\
\hline \multirow[t]{3}{*}{$1241 \mathrm{w}$} & $1244 \mathrm{vw}$ & $b_{2}$ & $1248(2.9)$ & $1251(2.8)$ & \\
\hline & $1224 \mathrm{vw}$ & $\mathrm{a}_{1}$ & $1212(0.7)$ & $1200(0.2)$ & \\
\hline & & $b_{2}$ & $1196(1.8)$ & $1195(1.1)$ & \\
\hline \multirow{2}{*}{1194 w } & $1196 \mathrm{vw}$ & $a_{1}$ & $1187(1.1)$ & $1190(0.6)$ & \\
\hline & $1175 \mathrm{sh}$ & $\mathrm{b}_{2}$ & $1186(0.3)$ & $1180(0.1)$ & \\
\hline \multirow[t]{2}{*}{$1160 \mathrm{w}$} & $1159 \mathrm{~m}$ & $a_{2}$ & $1159(0.0)$ & $1167(0.1)$ & \\
\hline & & $b_{2}$ & $1132(0.1)$ & $1125(0.0)$ & \\
\hline \multirow[t]{2}{*}{$1113 \mathrm{vw}$} & $1111 \mathrm{vw}$ & $\mathrm{a}_{1}$ & $1100(7.3)$ & $1101(0.9)$ & \\
\hline & & $b_{2}$ & $1091(5.7)$ & $1078(3.9)$ & \\
\hline \multirow[t]{4}{*}{1077 w } & $1073 \mathrm{~m}$ & $b_{1}$ & $1058(2.9)$ & $1065(2.7)$ & \\
\hline & & $a_{2}$ & $1054(0.0)$ & $1050(0.0)$ & \\
\hline & $1039 \mathrm{~m}$ & $a_{1}$ & $1036(0.1)$ & $1021(0.1)$ & \\
\hline & & $b_{2}$ & $1006(2.1)$ & $1000(0.2)$ & \\
\hline \multirow[t]{3}{*}{$1016 \mathrm{w}$} & & $\mathrm{b}_{1}$ & $985(0.8)$ & $993(0.6)$ & \\
\hline & 996 vw & $a_{2}$ & $981(0.0)$ & $984(0.7)$ & \\
\hline & $965 \mathrm{vw}$ & $a_{1}$ & $946(3.8)$ & $955(1.2)$ & \\
\hline \multirow[t]{2}{*}{$933 \mathrm{~m}$} & $935 \mathrm{vw}$ & $b_{1}$ & $939(0.7)$ & $938(0.6)$ & \\
\hline & $920 \mathrm{w}$ & $a_{2}$ & $909(0.0)$ & $910(0.0)$ & \\
\hline 879 vw & 885 w & $\mathrm{b}_{1}$ & $906(0.1)$ & $905(0.1)$ & \\
\hline \multirow[t]{2}{*}{$835 \mathrm{~m}$} & $835 \mathrm{vw}$ & $b_{2}$ & $846(1.6)$ & $848(0.9)$ & \\
\hline & 817 vw & $a_{1}$ & $845(0.0)$ & $844(0.1)$ & \\
\hline 796 vw & & $a_{2}$ & $810(0.0)$ & $818(0.0)$ & \\
\hline $774 \mathrm{vw}$ & 768 vs & $\mathrm{b}_{2}$ & $782(3.3)$ & $775(0.9)$ & \\
\hline 749 vw & $745 \mathrm{~s}$ & $b_{1}$ & $781(95.0)$ & $780(81.2)$ & \\
\hline $724 \mathrm{vw}$ & & $a_{2}$ & $740(0.0)$ & $730(0.0)$ & \\
\hline
\end{tabular}

a Infrared intensities (in parentheses) in $\mathrm{km} / \mathrm{mol}$.

b Estimated uncertainties in band positions are within $\pm 3 \mathrm{~cm}^{-1}$. Relative intensities: $\mathrm{vw}=$ very weak, $\mathrm{w}=\mathrm{weak}, \mathrm{m}=\mathrm{medium}, \mathrm{s}=\mathrm{strong}, \mathrm{vs}=\mathrm{very}$ strong, $\mathrm{sh}=\mathrm{shoulder}$.

c Unscaled DFT frequencies calculated using B3LYP/6-311+G(d,p) as described elsewhere [3].

d Anharmonics B3LYP/6-311 calculation using the $\mathrm{P}_{-} \mathrm{VMWCI}_{2}$ algorithm $[21,22]$.

e Eigenvector contains $6 \%$ contribution from $810+780 \mathrm{~cm}^{-1}$ combination.

f Eigenvector contains 6\% contribution from $2 \times 780 \mathrm{~cm}^{-1}$ overtone.

Some features present in the experimental spectra, such as the 562 and $454 \mathrm{~cm}^{-1}$ Raman bands of fluorene and 2-ethylfluorene, respectively, appear to be absent from the computed spectra, and are also attributed to dimer effects arising in crystals. For example, the coupling of vibrations of neighboring molecules-possibly caused by pi-pi interactions-is expected to shift the frequencies of some intramolecular modes and give rise to additional features in spectra. A few additional assignments to dimer vibrations are given in the tables. Calculations of coupled vibration frequencies for condensed-ring aromatics are presently under way in our laboratory and will be reported separately.

\section{Acknowledgements}

Part of the work described in this paper was performed at the Canadian Light Source, which is supported by the Natural Sciences and Engineering Research Council of Canada, the National Research Council Canada, the Canadian Institutes of Health Research, the Province of Saskatchewan, Western Economic Diversification Canada, and the University of Saskatchewan. Computer time for this study was provided by the computing facilities MCIA (Mésocentre de Calcul Intensif Aquitain) of the Université de Bordeaux and of the Université de Pau et des Pays de l'Adour. 


\section{Appendix A. Supplementary data}

Supplementary material related to this article can be found, in the online version, at http://dx.doi.org/10.1016/j.vibspec. 2014.07.003.

\section{References}

[1] K.H. Michaelian, B.E. Billinghurst, J.M. Shaw, V. Lastovka, Vib. Spectrosc. 49 (2009) 28-31.

[2] K.H. Michaelian, Q. Wen, B.E. Billinghurst, J.M. Shaw, V. Lastovka, Vib. Spectrosc. 58 (2012) 50-56.

[3] N. Sallamie, J.M. Shaw, Fluid Phase Equilibr. 237 (2005) 100-110.

[4] C. Obiosa-Maife, J.M. Shaw, Energy Fuels 25 (2011) 460-471.

[5] C. Boersma, A.L. Mattioda, C.W. Bauschlicher Jr., A.G.G.M. Tielens, L.J. Allamandola, Astrophys. J. 690 (2009) 1208-1221.

[6] C. Joblin, L. d'Hendecourt, A. Léger, D. Défourneau, Astron. Astrophys. 281 (1994) 923-936.

[7] J. Szczepanski, M. Vala, Astrophys. J. 414 (1993) 646-655.

[8] C. Boersma, C.W. Bauschlicher Jr., A. Ricca, A.L. Mattioda, E. Peeters, A.G.G.M. Tielens, L.J. Allamandola, Astrophys. J. 729 (2011) 1 (14 pp.).

[9] C.W. Bauschlicher, S.R. Langhoff, Spectrochim. Acta A 53 (1997) 1225-1240.

[10] C.W. Bauschlicher Jr., Chem. Phys. 233 (1998) 29-34.

[11] C.W. Bauschlicher Jr., S.R. Langhoff, Chem. Phys. 234 (1998) 79-86

[12] C.W. Bauschlicher Jr., Chem. Phys. 234 (1998) 87-94.

[13] C.W. Bauschlicher Jr., Chem. Phys. 262 (2000) 285-291.

[14] S.R. Langhoff, J. Phys. Chem. 100 (1996) 2819-2841.

[15] J. Oomens, G. Meijer, G. von Helden, J. Phys. Chem. A 105 (2001) 8302-8309.
[16] N. Gohaud, D. Bégué, C. Pouchan, Chem. Phys. 310 (2005) 85-96.

[17] D. Bégué, S. Elissalde, E. Pere, P. Iratcabal, C. Pouchan, J. Phys. Chem. A 110 (2006) 7793-7800.

[18] D. Bégué, P. Labéguerie, D.Y. Zhang-Negrerie, A. Avramopoulos, L. SerranoAndrés, M.G. Papadopoulos, Phys. Chem. Chem. Phys. 12 (2010) 13746-13751.

[19] D. Bégué, I. Baraille, P.-A. Garrain, A. Dargelos, T. Tassaing, J. Chem. Phys. 133 (2010) 034102 (13 pp.).

[20] D. Bégué, G.G. Qiao, C. Wentrup, J. Am. Chem. Soc. 134 (2012) 5339-5350.

[21] I. Baraille, C. Larrieu, A. Dargelos, M. Chaillet, Chem. Phys. 273 (2001) 91-101.

[22] D. Bégué, N. Gohaud, C. Pouchan, P. Cassam-Chenai, J. Liévin, J. Chem. Phys. 127 (2007) 164115 (10 pp.).

[23] M. Abo-Bakr, J. Feikes, K. Holldack, P. Kuske, W.B. Peatman, U. Schade, G. Wüstefeld, H.-W. Hübers, Phys. Rev. Lett. 90 (2003) 094801 (4 pp.).

[24] B. Billinghurst, T. May, L. Dallin, W. Wurtz, M. de Jong, K.H. Michaelian, Opt. Lett. 35 (2010) 3090-3092.

[25] J.M. Hume, G.I. Jenkins, Appl. Spectrosc. 18 (1964) 161-166.

[26] A. Bree, R. Zwarich, J. Chem. Phys. 51 (1969) 912-920.

[27] S.Y. Lee, B.Y. Boo, J. Phys. Chem. 100 (1996) 8782-8785.

[28] T. Thormann, M. Rogojerov, B. Jordanov, E.W. Thulstrup, J. Mol. Struct. 509 (1999) 93-104.

[29] C.R. Johnson, S.A. Asher, Anal. Chem. 56 (1984) 2258-2261.

[30] R. Rumelfanger, S.A. Asher, M.B. Perry, Appl. Spectrosc. 42 (1988) 267-272.

[31] Y.T. Chua, P.C. Stair, J. Catal. 213 (2003) 39-46.

[32] D.S. Cordeiro, P. Corio, J. Braz. Chem. Soc. 20 (2009) 80-87.

[33] S. Chakraborty, P. Das, S. Manogaran, P.K. Das, Vibr. Spectrosc. 68 (2013) $162-169$.

[34] J. Banisaukas, J. Szczepanski, M. Vala, S. Hirata, J. Phys. Chem. A 108 (2004 3713-3722.

[35] Q. Wen, K.H. Michaelian, Opt. Lett. 33 (2008) 1875-1877.

[36] M. Dehghany, K.H. Michaelian, Rev. Sci. Instrum. 83 (2012) 064901 (4 pp.).

[37] F. Spillebout, D. Bégué, I. Baraille, J.M. Shaw, Energy Fuels 28 (2014) 2933-2947. 